\title{
Gestión COLECTIVA Y CONJUNTA DE AGUAS: PERSPECTIVA JURÍDICA DE UNA DEUDA SUBTERRÁNEA*
}

[Collective and joint management of water: legal perspective of an underground debt]

\section{Daniela Rivera Bravo**}

\section{RESUMEN}

El trabajo analiza la gestión de las aguas subterráneas en Chile, evaluando el cumplimiento de las directrices normativas que establecen su manejo colectivo y conjunto con las superficiales. Para ello, se revisa la realidad y el estatuto jurídico de esta temática, constatando que tales directrices han fracasado en su implementación práctica. Además de identificar las razones de este fracaso, se

\section{ABSTRACT}

The paper analyzes the management of groundwater in Chile, evaluating compliance with legal guidelines that establish the collective and joint management of ground and surface water. For this purpose, the facts and the legal rules are reviewed, stating that the practical implementation of these guidelines has failed. As well as identifying the reasons for this failure, some ideas to overcome

RECIBIDO 24 de abril y ACEPTADO el 31 de mayo de 2016

* Trabajo realizado en el marco del Proyecto de Iniciación en Investigación No11130660 (2013-2016), auspiciado por el Fondo Nacional de Ciencia y Tecnología (FONDECYT-CONICYT), y que se titula "Particularidades del Derecho de Aguas Subterráneas. Instituciones y principios jurídicos en Chile”.

** Abogada, Universidad de Talca; Magíster en Ciencia Jurídica y Doctora en Derecho, Pontificia Universidad Católica de Chile. Investigadora y Profesora del Centro de Derecho y Gestión de Aguas, Pontificia Universidad Católica de Chile. Dirección postal: Alameda 340, Facultad de Derecho UC, of. 427. Correo electrónico: dirivera@uc.cl 
enuncian algunas ideas para enfrentar una de las más relevantes problemáticas de las aguas subterráneas.

\section{Palabras Clave}

Aguas subterráneas - gestión colectiva - organizaciones de usuarios. one of the most important issues of groundwater are set.

\section{KEYWORDS}

Groundwater - collective action water user organizations.

\section{INTRODUCCIÓN}

En Chile, si bien los titulares de derechos de aprovechamiento de aguas están individualmente dotados de un estatuto de libertad y autonomía, el ejercicio de dichos derechos (concretamente, el uso del recurso) está sujeto a las determinaciones que adopta en cada fuente natural u obra artificial un ente colectivo: la respectiva organización de usuarios. Así, la forma, oportunidad y volumen que puede ser extraído por cada titular son definidos, primero, por la competente junta de vigilancia (cuya jurisdicción abarca, por regla general, toda una fuente natural), y, luego, por la comunidad de aguas o asociación de canalistas de la correspondiente canalización u obra común. Dichas organizaciones adoptan sus acuerdos de distribución, para cada año o temporada, en función de la disponibilidad de aguas y de las características de los derechos de sus miembros.

La dinámica descrita es la tónica tradicional en materia de aguas superficiales; los ríos y canales han sido gestionados por las referidas organizaciones desde tiempos remotos. Pero algo muy distinto ocurre con las aguas subterráneas: ellas son utilizadas, mayoritariamente, de manera individual y aislada, sin instancias de control y administración comunitaria. La proliferación de esta individualidad, sumado a la carencia de un estatuto jurídico apropiado, se asocia a problemáticas cada vez más habituales y complejas, convirtiendo a la explotación de aguas subterráneas en una preocupación global. En efecto, una serie de dimensiones demuestra la vulnerabilidad de las aguas subterráneas y los efectos que su sobreexplotación acarrea: desequilibrio entre necesidades humanas y ambientales; peligros asociados (subsidencia o hundimiento de la tierra, aumento de posibilidades de terremoto e intrusión de agua marina a las fuentes de agua terrestre); afección a la salud de la población (producto de la contaminación); riesgos para la seguridad alimentaria y para la generación de energía (contexto en que el fracking está en el centro del debate en varios países); y aparición 
de conflictos (entre Estados, a propósito de acuíferos transfronterizos, y a nivel interno, entre los distintos usuarios y la Administración) ${ }^{1}$.

Todo indica que estamos frente a un paradigmático ejemplo de la denominada "tragedia de los comunes", a partir de la que han nacido numerosas teorías sobre cuál es la vía más óptima para administrar los recursos naturales comunes. Ni el Estado ni el mercado han logrado un éxito uniforme en este cometido; pero hay otras instituciones colectivas, que no se parecen ni al Estado ni al mercado, que han alcanzado resultados exitosos en este campo ${ }^{2}$.

¿Por qué las fórmulas asociativas o de gestión colectiva no han logrado implementarse masivamente respecto a las aguas subterráneas? ¿Es decisivo el hecho de ser un recurso que no está naturalmente a la vista y que no se conoce del todo? ¿Qué influencia tiene la precaria y desajustada regulación jurídica que existe sobre este tema? Éstas son algunas de las preguntas

${ }^{1}$ Gorelick, Steven and Zheng, Chunmiao, Global change at the groundwater management challenge, en Water Resources Research 51 (2015) 5, pp. 3031-3042. En similar sentido, constatando la contradicción que se da en California, donde, pese a depender fuertemente de las aguas subterráneas, han sido en gran medida desreguladas, ocasionando su explotación intensa e insustentable, ver KIPARSKY, Michael et al., Designing effective groundwater sustainability agencies: criteria for evaluation of local governance options (Berkeley, Wheeler Water Institute-Center for Law, Energy \& the Environment, UC Berkeley School of Law, 2016), p. 14. Comparando la explotación excesiva de este recurso en Tokio y California, ver Endo, Takahiro, Groundwater management: a search for better policy combination, en Water Policy 17 (2015), pp. 332-335. Sobre el caso español, y precisando que, aunque hay mejoras, la gestión del agua subterránea es todavía caótica, ver LlaMAS, M. Ramón et al., Groundwater in Spain: increasing role, evolution, present and future, en Environmental Earth Sciences 73 (2015), pp. 2567-2578. Respecto a India, mayor usuario de aguas subterráneas a nivel mundial, en que el $60 \%$ del territorio está afectado por problemas de disponibilidad y calidad de este recurso, ver Cullet, Philippe, Groundwater Law in India, en Journal of Environmental Law 26 (2014), pp. 55-56.

${ }^{2}$ Ostrom, Elinor, El gobierno de los bienes comunes. La evolución de las instituciones de acción colectiva ( $2^{\mathrm{a}}$ edición en español, traducción castellana de L. MERINO, Ciudad de México, Instituto de Investigaciones Sociales Universidad Nacional Autónoma de México y Fondo de Cultura Económica, 2011), p. 36. Aplicando la teoría y los principios de Ostrom a un caso australiano, y postulando que la efectiva participación de los usuarios de aguas subterráneas en su gestión, permite hacer más sustentable su explotación, ver SARKER, Ashutosh et al., Managing groundwater as a common-pool resource: an australian case study, en Water Policy 11 (2009), pp. 599610. Del mismo modo, verificando la concurrencia de los principios de diseño de Ostrom en comunidades de aguas subterráneas de España, ver SCHLAGER, E. y LóPEZGunn, E., Collective systems for water management: is the tragedy of the commons a myth?, en Rogers, Peter - Llamas, M. Ramón - Martínez-Cortina, Luis (editores), Water crisis: myth or reality? (Londres, Taylor \& Francis/Balkema, 2006), pp. 44-48. 
que guiarán el desarrollo del presente estudio, cuyo objeto es constatar y entender el fracaso de la gestión colectiva de las aguas subterráneas, y de éstas, conjuntamente, con las superficiales, en el modelo chileno.

Para el logro de este propósito, el texto se divide en cinco apartados centrales: el primero contiene algunas referencias normativas históricas y vigentes sobre la regulación de las organizaciones de usuarios; el segundo se enfoca en el estatuto y realidad de las organizaciones de usuarios de aguas subterráneas; el tercero revisa la procedencia y conveniencia de la gestión colectiva de aguas subterráneas; el cuarto identifica y sistematiza las principales causas que han estado detrás del fracaso de esta gestión colectiva; y, el quinto, efectúa algunos aportes en torno al crucial rol de las juntas de vigilancia. Todo lo anterior, en un análisis efectuado tras haberse cumplido diez años desde la incorporación al Código de Aguas (CA) de una serie de modificaciones que se orientaban, precisamente, a la promoción de la gestión colectiva y conjunta de aguas superficiales y subterráneas (Ley No20.017, de 2005).

\section{ANTECEDENTES REgulatorios DE LA GESTIÓN COLECTIVA} DE AGUAS

Para tener una mejor ilustración de las reglas jurídicas que regulan este asunto, se efectúa un breve recorrido por las principales normas sobre organizaciones de usuarios. Demostrando el preponderante rol de tales organizaciones en nuestro sistema, cabe recordar que una de las primeras leyes sectoriales fue la relativa a asociaciones de canalistas, de 1908 .

1. Remota base regulatoria de las organizaciones de usuarios: Ley No2.139, de 1908

Pese al transcurso del tiempo, la simple lectura de este texto evidencia que no hemos innovado demasiado en lo relativo a organizaciones de usuarios. Prácticamente las mismas directrices son las que están presentes en el Código de Aguas vigente, dictado 70 años después de la referida Ley No2.139. En esta Ley: a) se reconocía el carácter de persona jurídica a las asociaciones que formaren dueños de canales para tomar agua de una corriente matriz, repartirla entre los accionistas y mejorar acueductos (arts.1 y 20); b) se advertía explícitamente que el agua del canal no era de la asociación, sino de dominio de los accionistas (art.2); c) se disponía que la determinación de los derechos de agua de los accionistas se hacía en función de unidades de medición, tales como regadores u otra establecida en los estatutos de la asociación (art.4); d) se entregaba a un directorio la administración de la asociación, cuyos deberes y atribuciones eran los 
fijados en esta misma ley (que les concedía, por ejemplo, facultades presupuestarias y jurisdiccionales) o en los estatutos (arts.10, 11 y 17); e) se aludía a las comunidades de aguas preexistentes, otorgándoles la posibilidad de acogerse a los términos de esta Ley (art.21).

Todas estas comunidades y asociaciones se enfocaban en aguas superficiales; su marco de actuación surgía de una obra típica: la bocatoma de un canal. Ninguna referencia, por tanto, a las aguas subterráneas.

\section{Mayores desarrollos en los Códigos de Aguas de 1951 y 1967}

Debido a que ambos cuerpos normativos tenían idénticas prescripciones en este punto, la enunciación de su contenido central se efectúa conjuntamente:

a) Triple clasificación de las organizaciones de usuarios. A diferencia de la Ley No2.139, que abordó exclusivamente las asociaciones de canalistas, los Códigos de 1951 y 1967 incorporaron la tipología de organizaciones que conocemos hasta el día de hoy: asociaciones de canalistas, comunidades de aguas y juntas de vigilancia.

b) Asociaciones de canalistas. Respecto a ellas pueden consignarse las siguientes orientaciones: i) el hecho que las originaba era la existencia de varias personas con derechos de aprovechamiento en las aguas de un mismo cauce artificial (arts.81 CA 1951 y 88 CA 1967); ii) su objeto era tomar las aguas del caudal matriz y repartirlas entre los asociados; construir, explotar, conservar y mejorar obras y acueductos comunes; y, ejecutar los actos y contratos relacionados al fin de la asociación (arts.81 CA 1951 y 88 CA 1967); iii) se les concedía el rango de personas jurídicas, y podían conformarse convencional o judicialmente; en ambos supuestos se requería aprobación del Presidente de la República (arts.82 CA 1951 y 89 CA 1967); iv) el derecho de los accionistas se definía por unidades denominadas acciones, las cuales correspondían a una parte alícuota de las aguas del acueducto respectivo (arts.90 CA 1951 y 97 CA 1967); v) se afirmaba que el derecho de aprovechamiento y el cauce que conducía las aguas no era de la asociación, sino de dominio de los accionistas (arts.94 CA 1951 y 101 CA 1967); vi) las obligaciones de los asociados estaban expresamente delimitadas (arts.106 CA 1951 y 113 CA 1967); vii) se contemplaba la reunión de los accionistas en juntas generales, que podían ser ordinarias o extraordinarias (arts.107 y siguientes CA 1951 y 114 y siguientes CA 1967); viii) su administración se confiaba a un directorio, al cual se encomendaban varias atribuciones y deberes (arts.123 y siguientes CA 1951 y 129 y siguientes CA 1967).

c) Comunidades de aguas. Sus directrices centrales eran: i) el origen de la comunidad estaba dado por la concurrencia de dos o más personas 
aprovechando aguas conducidas por un mismo cauce artificial, sin que existiere asociación de canalistas ni otra convención particular sobre tal aprovechamiento (arts.146 CA 1951 y 152 CA 1967); ii) la forma de administración dependía del número de comuneros: si eran más de cinco, procedía la elección de un directorio; en caso contrario, surgía la figura del administrador (arts. 150 CA 1951 y 156 CA 1967); iii) si bien la comunidad emanaba de una situación de hecho (reunión de dos o más personas con derechos de aprovechamiento en un cauce artificial), se regulaba un procedimiento de conformación judicial (arts.151 y siguientes CA 1951 y 157 y siguientes CA 1967); iv) se reconocía la posibilidad de transformar una comunidad de aguas en asociación de canalistas (arts.158 CA 1951 y 164 CA 1967).

d) Juntas de vigilancia. Sus reglas básicas podrían enunciarse como sigue: i) estaban conformadas por las personas naturales, jurídicas, asociaciones de canalistas y comunidades que aprovechaban el agua de una misma cuenca u hoya hidrográfica (arts.159 CA 1951 y 165 CA 1967); ii) su propósito era la administración y distribución de aguas a que tenían derecho sus miembros; la explotación, construcción y conservación de obras de aprovechamiento común; y la ejecución de otros fines que les encomendaba la ley (arts.161 CA 1951 y 167 CA 1967); iii) se contemplaba la división de derechos de aprovechamiento de aguas en acciones (arts.163 CA 1951 y 169 CA 1967); iv) su organización se producía por vía judicial (arts.164 y siguientes CA 1951 y 170 y siguientes CA 1967); v) se definían una serie de atribuciones y deberes de su directorio (arts.171 CA 1951 y 177 CA 1967). No obstante ello, se establecía que si eran sólo dos los canales involucrados, la administración correspondía a un administrador (arts.167 CA 1951 y 173 CA 1967); vi) se incluían dos importantes figuras en el proceso de distribución: repartidores de aguas y celadores (arts.174 y siguientes CA 1951 y 180 y siguientes CA 1967).

e) Olvido de las aguas subterráneas. Aun cuando no se señalaba de modo expreso, todas estas entidades de gestión colectiva actuaban en el ámbito de las aguas superficiales. No queda duda de ello en las asociaciones de canalistas y comunidades de aguas, basadas en el ejercicio de derechos a través de un cauce artificial común (canalización). Y, tratándose de las juntas de vigilancia, pese a que inicialmente se disponía que su jurisdicción se extendía sobre todos los derechos de una misma cuenca u hoya hidrográfica, luego se indicaba, como uno de los puntos decisorios del procedimiento judicial de su conformación, la determinación de los "canales" sometidos a su accionar; ninguna alusión análoga existía respecto a obras de extracción de aguas subterráneas. 


\section{Código de Aguas de 1981 y su superficial reforma del año 2005}

El Código de 1981 mantuvo en este tema los mismos lineamientos de sus antecesores de 1951 y 1967, por lo que se omiten en esta parte los aspectos medulares de las comunidades de aguas ${ }^{3}$, asociaciones de canalistas y juntas de vigilancia.

Para los fines de este estudio, son interesantes las modificaciones introducidas por la Ley No 20.017, de 2005, al párrafo de las organizaciones de usuarios, pues su objetivo fue la inclusión de las aguas subterráneas en la jurisdicción de estos entes colectivos. Sin embargo, una escasa prolijidad y profundidad en la técnica legislativa es notoria en los cambios realizados ${ }^{4}$; no fue mucho más que la mera incorporación de expresiones aisladas, a saber:

a) En el art.63 CA se estableció que la declaración de una zona de prohibición para nuevas explotaciones origina una comunidad entre todos los usuarios de aguas subterráneas existentes en tal ámbito. Esta conformación forzada ya se contemplaba para las declaraciones de áreas de restricción, por lo que la reforma apuntó a establecer la misma consecuencia para la zona de prohibición ${ }^{5}$.

b) En el art.186 CA, que enuncia la triple tipología de organizaciones de usuarios que contempla nuestro régimen, se reemplazó la frase "o usan en común la misma obra de captación de aguas subterráneas" por "o aprovechan las aguas de un mismo acuífero". Además, se sustituyó la noción "canal matriz" por "caudal matriz".

c) En el art.263 CA, que encabeza el párrafo relativo a las juntas de vigilancia, se incorporó la frase "superficiales o subterráneas" para especificar el

${ }^{3}$ El Código de 1981 incluye disposiciones particulares para un tipo especial de comunidad: de obras de drenaje (arts.252 a 256).

${ }^{4}$ En ese sentido, ver Arévalo, Gonzalo, Comunidades de aguas subterráneas: dificultades en su organización y ejercicio, en Actas de Derecho de Aguas 3 (2013), p. 189.

${ }^{5}$ En la discusión de esta prescripción se advirtió que “.... a través de esta norma se hace extensiva la institución de las comunidades de aguas que se forman por el solo ministerio de la ley en el caso de las áreas de restricción, a las zonas de prohibición. En ambas instituciones es indispensable que sean los propios usuarios los que controlen el manejo de los recursos y las organizaciones de usuarios son los organismos adecuados para ello." (Historia de la Ley No20.017, de 2005, p. 1252. Disponible en: http://www.leychile.cl/Consulta/portada_hl?tipo_norma=XX1\&nro_ ley=20017\&anio=2015. Fecha de consulta: 20 de junio de 2015).

6 “...se trata de una adecuación normativa dado que se permitirán las comunidades de aguas sobre un mismo acuífero, para lo cual se deben eliminar las comunidades de aguas subterráneas que se forman por el solo hecho de utilizar una misma obra de captación, esto, con el objetivo de impedir que se superpongan dos comunidades de aguas sobre una misma fuente..." (Historia de la Ley No20.017, de 2005, p. 1286). 
tipo de agua que pueden aprovechar las personas naturales o jurídicas y las organizaciones que conforman esta entidad ${ }^{7}$. A su vez, entre los datos que deben incluirse en el extracto de la escritura de constitución y estatutos de una junta, se mencionan los "acuíferos" sobre los que tiene jurisdicción.

d) En el art.266 CA se define el objeto de las juntas de vigilancia, incluyendo la administración y distribución de las aguas a que tienen derecho sus miembros en las "fuentes" naturales (con anterioridad se hablaba de "cauces") ${ }^{8}$.

En su momento se planteó introducir explícitas referencias a derechos de aguas "subterráneas" y a aguas "subterráneas" en el art. 274 CA, que menciona los deberes y atribuciones del directorio de una junta de vigilancia. Sin embargo, se estimó que era preferible establecerlo de forma genérica, aunque, para efectos de historia legislativa, se dejó constancia que en esta disposición deben entenderse aludidos todos los derechos de aprovechamiento y aguas de una cuenca? .

4. Decreto No203, de 2014, que establece el Reglamento sobre normas de exploración y explotación de aguas subterráneas

Este texto dedica un apartado particular a las comunidades de aguas subterráneas, no refiriéndose a las juntas de vigilancia. Se omite, por tanto, una de las bases fundamentales de la gestión colectiva de las aguas subterráneas. Sin perjuicio que luego se efectúa un análisis más detenido de algunos de sus preceptos, el Reglamento tiene las siguientes prescripciones:

a) Como hipótesis de hecho que origina una comunidad de este tipo, señala la existencia de dos o más personas que aprovechen aguas de un mismo "sector hidrogeológico de aprovechamiento común" (art.37 Decreto No203, de 2014), alterando la expresión utilizada por la ley a este respecto (el Código de Aguas habla de "acuífero").

b) Entre los deberes y atribuciones del directorio figura, en primer lugar, la distribución de las aguas del sector hidrogeológico de aprovechamiento

7 Durante el análisis de este cambio se advirtió que era innecesario, pues las juntas de vigilancia ya tenían jurisdicción sobre toda la cuenca u hoya hidrográfica, comprendiendo aguas superficiales y subterráneas. No obstante, la Comisión de Obras Públicas estimó conveniente permitir de modo explícito la organización de los usuarios de aguas subterráneas. Véase Historia de la Ley No20.017, de 2005, pp. 1026-1027.

8 "En discusión esta indicación se explicó que se trata de una adecuación normativa necesaria por la incorporación de las aguas subterráneas a las juntas de vigilancia..." (Historia de la Ley No20.017, de 2005, p. 1287).

${ }^{9}$ Ver Historia de la Ley No20.017, de 2005, pp. 1032-1033. 
común entre los comuneros a prorrata de sus derechos (art.38 No 1 Decreto No203, de 2014).

c) Se alude al surgimiento forzado/obligatorio de comunidades de aguas subterráneas en aquellos sitios declarados áreas de restricción o zonas de prohibición (art.39 Decreto No 203, de 2014).

d) Comparándolo con el escenario anterior a su dictación, en que se aplicaba la Resolución No425, de 2007, de la Dirección General de Aguas (DGA), se acentúa la potestad de esa entidad para exigir la instalación de sistemas de medición de cantidad y calidad de aguas subterráneas; ahora no se limita sólo a los supuestos de prohibición o restricción, sino que se extiende a la generalidad de las comunidades o usuarios individuales, independientemente de la existencia de la mencionada declaración (art.40 Decreto No203, de 2014).

\section{ORgANIZACIONES DE USUARIOS DE AGUAS SUBTERRÁNEAS}

Dadas las particularidades de las aguas subterráneas, su captación se produce a través de obras (pozos, galerías, zanjas, drenes, entre otros) construidas y operadas por cada titular de derechos de aprovechamiento. Pueden existir obras comunes, que permiten a dos o más particulares extraer el agua que les corresponde; pero aún en ese supuesto, tal extracción ocurre habitualmente de manera individual por los usuarios respectivos, quienes se limitan a compartir una infraestructura física determinada. A esta realidad aludía el Código de Aguas antes de la reforma del año 2005, cuando posibilitaba la conformación de una comunidad entre quienes usaren la misma obra de captación subterránea. En ese modelo no hay gestión colectiva del recurso, sino sólo una agrupación de titulares en torno a una obra común.

En el régimen actual, la legislación propicia el ejercicio de los derechos de aprovechamiento a través de organizaciones de usuarios, lo cual se asocia a objetivos de gestión colectiva, conjunta y localizada de un recurso escaso y limitado. Ello está en sintonía con varios estudios y recomendaciones internacionales en torno a la gobernanza del agua, los cuales sostienen que un sistema local, que involucre a los usuarios, es idóneo para alcanzar mayor sostenibilidad y eficiencia en su utilización ${ }^{10}$.

${ }^{10}$ Afirmando que la gestión del agua debe hacerse en una escala apropiada, en un sistema integrado de cuencas que refleje las condiciones locales, ver ORGANISATION FOR ECONOMIC COOPERATION AND DEVELOPMENT (OECD), Principles on water governance (s/l, OECD, 2015), p. 9. Sobre las ventajas y desafíos de un manejo y control local de las aguas subterráneas en California, ver SAndino, David, California's groundwater management since the Governos's Commission Review: the consolidation 
1. Autogobierno de las organizaciones de usuarios: una forma de localización del Derecho de Aguas a cada cuenca

Una de las directrices fundamentales del Derecho de Aguas chileno es el autogobierno de las organizaciones de usuarios. Ello se materializa en el reconocimiento de exclusivas atribuciones y deberes a las juntas de vigilancia, asociaciones de canalistas y comunidades de aguas, y, luego, en las limitadas potestades que la autoridad administrativa (DGA) detenta respecto a las funciones que le son propias a esos entes colectivos (principalmente, distribución y reparto de aguas) ${ }^{11}$.

Son las organizaciones de usuarios las que fijan, en sus estatutos, los parámetros conforme a los cuales deberán ordenarse y funcionar (por cierto, respetando las reglas legales). De esta forma, lo que se genera es un Derecho de Aguas más territorializado y localizado para cada ámbito espacial. Sin embargo, el Código de Aguas, al normar las organizaciones de usuarios, define detalladamente el contenido de tales estatutos, dejando sólo algunos supuestos aislados en que los usuarios pueden efectuar alteraciones ${ }^{12}$.

Así, y aunque todo revela que la intención del legislador era vigorizar la actuación conjunta de los titulares de derechos de aprovechamiento, hay una serie de preceptos que contrarrestan sus potestades de autorregulación ${ }^{13}$.

of local control, en McGeorge Law Review 36 (2005), pp. 482-494; LegisLATIVE ANALYST'S OfFice (LAO), Improving management of the State's groundwater resources (Sacramento, LAO Ediciones, 2010), pp. 20-24; y, KipARSKY, Michael et al., cit. (n. 1), pp. 13-19. Precisando que los problemas de aguas subterráneas son globales, pero deben resolverse a nivel local, según los factores sociales, políticos y económicos de cada área, ver ENDO, Takahiro, cit. (n. 1), p. 346. Señalando que las aguas subterráneas son incluso más locales que las superficiales, y que, por ende, deben regularse y gestionarse en esa instancia, bajo estándares de subsidiariedad y descentralización, ver Cullet, Philippe, cit. (n. 1), pp. 68-70.

${ }^{11}$ En esta línea, ver RojAs, Christian, La distribución de aguas por las juntas de vigilancia, en Revista de Derecho Administrativo Económico 2 (2003), p. 317; y, EL MISMO, La categoría jurídica de los "servicios privados de interés publico": el caso de las juntas de vigilancia de los ríos, en Revista Chilena de Derecho 41 (2014) 1, p. 200. Sobre la importancia y significado del autogobierno, ver Ostrom, Elinor, El gobierno, cit. (n. 2), p. 14.

12 Esta situación es cercana a la de los individuos que viven atrapados en un "mundo de un solo piso", mencionada por Ostrom, que ocurre cuando no hay instancias de autoorganización o autogestión, sino que las soluciones vienen dadas, pudiendo solamente definirse estrategias dentro de tales límites. Ver Osтrom, Elinor, El gobierno, cit. (n. 2), p. 113.

${ }^{13}$ Percibiendo esta problemática como un obstáculo al autogobierno, ver VERGARA, Alejandro, Autogobierno en la gestión de las aguas, en Actas de Derecho de Aguas 3 (2013), p. 170. Proponiendo los conceptos de "autorregulación regulada" y "servicio privado de interés público” para la labor de las juntas de vigilancia, ver RoJAs, Chris- 
Están impedidos de fijar autónomamente los detalles más básicos de su organización ${ }^{14}$; la ley desarrolla esta tarea en su lugar, lo cual no siempre ocurre de la manera más adecuada ${ }^{15}$.

Se trata de una cuestión que debe ser prontamente revisada; esta normativa proviene de los primeros pronunciamientos legislativos dictados en el país en torno a las aguas. Además, cabe advertir que el reconocimiento mínimo del derecho de los usuarios a organizarse y a fijar sus reglas, sin intromisión de autoridades externas, es uno de los principios de diseño característicos que Ostrom identifica en las instituciones de larga duración y exitosas en el manejo y control sostenible de recursos comunes, como el agua ${ }^{16}$.

\section{Comunidades de aguas subterráneas}

La conformación de estas entidades se contempla a través de dos vías:

a) Voluntaria o convencional. El art.186 CA dispone que: "Si dos o más personas tienen derechos de aprovechamiento en las aguas de un mismo canal, embalse, o aprovechan las aguas de un mismo acuífero, podrán reglamentar la comunidad que existe como consecuencia de este hecho, constituirse en asociación de canalistas o en cualquier tipo de sociedad, con el objeto de tomar las aguas del caudal matriz, repartirlas entre los titulares de derechos, construir, explotar, conservar y mejorar las obras de captación, acueductos y otras que sean necesarias para su aprovechamiento. En el caso de cauces naturales podrán organizarse como junta de vigilancia." ${ }^{17}$

Como puede apreciarse, esta disposición genérica admite que las comunidades pueden organizarse también en materia de aguas subterráneas. Ahora bien, si se da el supuesto fáctico descrito en la norma (dos o más personas aprovechando las aguas de un mismo acuífero), existe igualmente, aunque no esté formalizada, una comunidad de hecho, lo que constituye la regla general en este escenario.

b) Forzada u obligatoria. Los artículos 63 y 65 del Código de Aguas y

tian, Autogestión y autorregulación regulada de las aguas. Organizaciones de usuarios de aguas (OUA) y juntas de vigilancia de rios, en Ius et Praxis 20 (2014) 1, pp. 146-158; y, El MiSMO, La categoría, cit. (n. 11) pp. 197-201.

${ }^{14}$ Rojas, Christian, La distribución, cit. (n. 11), p. 317.

15 Piénsese en las propias comunidades de aguas subterráneas, las cuales, pese a sus especificidades, deben regirse, casi en su integridad, por las mismas prescripciones que las comunidades de aguas superficiales.

${ }^{16}$ Ostrom, Elinor, El gobierno, cit. (n. 2), pp. 165 y 183-184; y, LA MISMA, Comprender la diversidad institucional (traducción castellana de M. Moro, Oviedo, KRK, 2013), pp. 603 y 622-625.

${ }^{17}$ En similar línea se encuentra el art.37 del Decreto No203, de 2014, que emplea la expresión "sector hidrogeológico de aprovechamiento común" en lugar de "acuífero". 
39 del Decreto No203, de 2014, contemplan el surgimiento, por el sólo ministerio de la ley, de comunidades de aguas subterráneas cuando se declare zona de prohibición o área de restricción en un acuífero o sector hidrogeológico de aprovechamiento común ${ }^{18}$.

Ante estas declaraciones, existe el deber legal de organizar las comunidades de aguas subterráneas correspondientes. Las resoluciones de la DGA que decretan zonas de prohibición o áreas de restricción, precisan que deberá promoverse la formalización de las comunidades, estableciendo incluso un plazo para ello, que suele ser de noventa días contado desde la fecha de publicación de la resolución respectiva en el Diario Oficial ${ }^{19}$.

De acuerdo a información oficial, entre los años 1997 y 2015 se decretaron 144 áreas de restricción y seis zonas de prohibición en el país ${ }^{20}$. Estas cifras, según se revisa infra, no coinciden con el número de comunidades de aguas subterráneas que efectivamente se han organizado en la práctica.

\section{Inclusión de los derechos de aguas subterráneas en las juntas de vigilancia}

Luego del año 2005, hay disposiciones legales que establecen, de modo vago, pero expreso, que las aguas subterráneas de la cuenca son parte del espacio competencial de las juntas de vigilancia. Sin embargo, el Decreto No203, de 2014, no contiene ningún pronunciamiento sobre las juntas de vigilancia, enfocándose sólo en las comunidades; una muestra de la desconexión, superficialidad y falta de visión sistémica con que son reguladas las aguas subterráneas.

4. Constatación empirica: escasa recepción de fórmulas de gestión colectiva de aguas subterráneas

Si observamos la realidad, todo evidencia que las organizaciones de usuarios no están operando en materia de aguas subterráneas; a saber:

a) Muy pocas comunidades se han organizado y funcionan como tales. Según datos emanados de la DGA, a la fecha existirían once comunidades

${ }^{18}$ Con relación a este punto, Carrasco afirma que la comunidad no nace por el sólo ministerio de la ley, sino a partir de una resolución administrativa de la DGA. Ello sería peligroso, pues se estaría formando discrecionalmente una asociación, lo que es contrario al principio de reserva legal y a la libre asociación. Véase CARRASCO, Edesio, Comentarios al nuevo régimen de aguas subterráneas a partir de la reforma al Código de Aguas de 2005, en Revista de Derecho Universidad Católica del Norte 14 (2007) 2, pp. 62-63.

19 Ese plazo es desajustado al extenso período que suele tardar la organización completa de una entidad de esta índole. Ello tiene varias causas, pero el registro/ catastro en la DGA es una de las actuaciones que acostumbra a demorar más tiempo.

${ }^{20}$ Ministerio de Obras Públicas y Dirección General de Aguas, Atlas del Agua. Chile 2016 (Santiago, MOP, 2016), pp. 94-97. 
de aguas subterráneas registradas en el Catastro Público de Aguas (CPA): una en Copiapó, en la III región del país, y otras diez en la V región ${ }^{21}$. Estas últimas fueron formalizadas recién el año 2015 en el marco de un programa dirigido por la propia $\mathrm{DGA}^{22}$. Y hay otras comunidades, que han sido legalmente constituidas, pero que se encuentren tramitando su incorporación al CPA, cuestión que puede demorar bastante tiempo en producirse.

b) Sólo es posible encontrar, en los estatutos de algunas juntas de vigilancia $^{23}$, la afirmación de que forman parte de ellas todos los titulares de derechos de aguas superficiales y subterráneas de la cuenca. Ello no pasa de ser una bien intencionada declaración, meramente nominal, pues las aguas subterráneas siguen estando fuera de la actividad de estos entes ${ }^{24}$.

Por lo tanto, habiendo transcurrido más de diez años desde la incorporación explícita de las aguas subterráneas al párrafo de las organizaciones de usuarios (Ley No20.017, de 2005), puede sostenerse que tales prescripciones han fracasado en su materialización práctica. Las aguas subterráneas siguen siendo usadas y gestionadas, mayoritariamente, de manera individual y aislada por cada titular de derecho de aprovechamiento, sin controles efectivos y sin estrategias de manejo conjunto con las aguas de la superficie. La ausencia de organizaciones de usuarios en este campo impide la implementación de medidas de aprovechamiento sustentable y pacífico de este recurso, lo que hace previsible un importante nivel de competitividad y conflictividad ${ }^{25}$.

${ }^{21}$ La falta de conformación de comunidades atenta contra la importancia de este tipo de entes en la gestión de los acuíferos, lo cual ha sido destacado por VERGARA, Alejandro, Crisis institucional del agua. Descripción del modelo, crítica a la burocracia y necesidad de tribunales especiales (Santiago, LegalPublishing Chile, 2014), p. 181.

${ }^{22}$ Ministerio de Obras Públicas y Dirección General de Aguas, cit. (n. 20), pp. 120-122.

${ }^{23}$ Cuarenta y seis organizaciones de esta índole están registradas en el CPA a nivel nacional. Ver Ministerio de Obras Públicas y Dirección General de Aguas, cit. (n. 20), pp. 120-123.

${ }^{24}$ Se infringe de ese modo el mandato de los arts.263 y 272 CA, cuestión que ha sido remarcada por Vergara, Alejandro, Autogobierno, cit. (n. 13), pp. 172-173, y, El mismo, Crisis, cit. (n. 21) pp. 385-387.

25 Donoso, Guillermo, Integrated water management in Chile, en MartínezSantos, Pedro - Aldaya, Maite - Llamas, M. Ramón (editores), Integrated water resources management in the $21^{\text {st }}$ century: revisiting the paradigm (Londres, CRC Press/ Balkema, 2014), p. 222. 


\section{IV. ¿Pueden y deben las aguas Subterráneas gestionarse COLECTIVAMENTE?}

Pese a que las aguas subterráneas están disponibles en mayor cantidad (y mejor calidad muchas veces) a nivel mundial, han sido olvidadas o relegadas a un segundo plano en las legislaciones; ocultas no sólo en el seno de la tierra, sino, además, tras las superficiales. Es gráfico el paralelismo que se da en los regímenes que contemplan organizaciones de usuarios para la gestión de las aguas: las relativas a aguas superficiales tienen una tradición añosa, y un importante reconocimiento social; las vinculadas a aguas subterráneas aún no logran siquiera acercarse al protagonismo de aquéllas, siendo todavía inexistentes en varios países.

Para entender este fenómeno, es necesario preguntarse primero si es posible, conveniente y procedente la gestión colectiva de las aguas subterráneas, al estilo de las superficiales. A ello se destinan los apartados que siguen.

\section{Una realidad propia y característica, distinta a la de aguas superficiales}

El aprovechamiento de las aguas subterráneas se produce de manera solitaria, a través de obras de extracción individuales y usualmente dentro de terrenos de propiedad privada (por ende, con acceso restringido). Todos estos elementos complican la inserción de las aguas subterráneas en instancias colectivas (organizaciones de usuarios clásicas), las cuales se enfocan en objetivos distintos: coordinación y acuerdos grupales para el uso y distribución de aguas; control y fiscalización permanente de las obras de aprovechamiento y de la utilización del recurso; y, estructuración en torno a obras artificiales comunes.

En el caso de las aguas subterráneas, lo "común" entre los titulares de derechos de aprovechamiento de una misma fuente natural se reduce a esta última (el acuífero, en términos de la ley, o el sector hidrogeológico de aprovechamiento común, según el reglamento); no suelen haber obras compartidas y todos tienen acceso directo y separado a dicha fuente natural. Los usuarios no requieren integrarse a ninguna agrupación para ejercer sus derechos; contrario sensu, la sola idea les puede resultar incómoda, pues implica someterse al control y accionar de un ente que, al menos en principio, es extraño e inconveniente en comparación a su posición de titulares individuales.

Así, el punto de partida en la revisión de la procedencia de la gestión colectiva de las aguas subterráneas es una cuestión obvia, pero que no siempre se considera: estamos ante un escenario distinto al de las aguas superficiales; la relación entre el titular del derecho y el agua subterránea es más directa (construcción de obra individual, situada en inmueble privado 
o de un tercero que lo ha autorizado, y que permite extraer el recurso con un margen de libertad amplio, pues las probabilidades de control externo no son frecuentes ${ }^{26}$.

Por estas razones, las aguas subterráneas se han convertido en una de las hipótesis por excelencia de la famosa tragedia de los comunes ${ }^{27}$ : un recurso que sería objeto de estudios y visión conjunta (con las superficiales) en la etapa de asignación de derechos de aprovechamiento, pero que luego, dada la ausencia de fórmulas de gestión colectiva, queda entregado a las decisiones aisladas de cada titular. En este ámbito, existiría sobreotorgamiento generalizado de derechos de aguas subterráneas entre la primera y la sexta región del país, y casos de sobreexplotación comprobados y otros en análisis en varios puntos ${ }^{28}$.

\section{Un recurso común que debe manejarse comunal o colectivamente}

Cuando las aguas son asignadas a particulares, bajo la fórmula de derechos de aprovechamiento constituidos o reconocidos, adquieren la naturaleza de bien común: los usos de cada titular producen efectos para sus pares; son gestionadas colectivamente por la organización competente en la fuente natural u obra artificial; la disponibilidad se define en cada temporada para el conjunto de usuarios, y, conforme a ello, se adoptan los acuerdos de distribución o reparto. No obstante, las aguas subterráneas, también recurso común, se manejan individualmente, produciendo un contrasentido irreconciliable.

Por ello, y sin perjuicio de las complejidades de las aguas subterráneas, que requieren matices propios, la actuación colectiva y coordinada de todos los usuarios de una misma fuente, es necesaria para una más adecuada ges-

${ }^{26}$ Destacando las particularidades de las aguas subterráneas, Embid afirma que sus conflictos aparecen más fácilmente y son más difíciles de resolver que los concernientes a aguas superficiales; ello, atendidas las características de los diversos tipos de acuíferos, que no siempre son vinculables a las aguas superficiales. Ver EMBID, Antonio, El Acuerdo sobre el sistema del Acuifero Guarani del 2 de agosto de 2010 en el marco de la incipiente regulación general de las aguas subterráneas, en Derecho de Aguas, Tomo $V$ (Bogotá, Universidad Externado de Colombia, 2013), p. 185. Con una similar orientación, ver ArÉvalo, Gonzalo, cit. (n. 4), pp. 189-190.

27 "La teoría convencional supone que cuando los individuos se enfrentan a un dilema debido a externalidades creadas por la acciones de otros, realizarán sólo cálculos estrechos y de corto plazo que llevarán a todos los individuos a dañarse a sí mismos y a los otros sin poder encontrar maneras de cooperar para superar el problema." (Ostrom, Elinor, El gobierno, cit. (n. 2), p. 10.

${ }^{28}$ Ministerio de Obras Públicas y Dirección General de Aguas, Estrategia Nacional de Recursos Hídricos (Santiago, MOP, 2013), pp. 22 y 24. 
tión de este recurso ${ }^{29}$. Ello no significa sostener que esta opción es la única procedente y que está exenta de dificultades; sin embargo, es la que ofrece mejores posibilidades de adaptación en nuestro medio ${ }^{30}$. El momento actual podría ser el propicio para impulsar esta tarea y poner en sintonía ley y realidad. Varias de nuestras fuentes subterráneas muestran síntomas severos

29 En este sentido, desde una perspectiva general, ver Llamas, M.R. y MarTíNEZ-SANTOS, P., Intensive groundwater use: silent revolution and potencial source of social conflicts, en Journal of Water Resources Planning and Management (2005), pp. 339-340; MECHLEM, Kerstin, Groundwater governance: a global framework for country action. Legal and institutional frameworks (Rome, Groundwater Governance, 2012), pp. 29-31; NANNI, Marcella, Legislation as a tool in support of adaptive water management in response to climate change, en Water International 37 (2012) 6, pp. 633-634; Holley, Cameron y SinClair, Darren, Deliberative participation, environmental law and collaborative governance: insights from surface and groundwater studies, en Environmental and Planning Law Journal 30 (2013) 32, pp. 32-37 y 50-55; y, ORGANISATION FOR ECONOMIC COOPERATION AND DEVELOPMENT (OECD), cit. (n. 10), pp. 2, 9 y 12. Para el caso norteamericano, ver MacNaughton, Ann y Folk-Williams, John, Engaging stakeholders for sustainable water resource solutions, en Natural Resources \& Environment 18 (2003) 2, p. 40; y, KiparSKY, Michael et al., cit. (n. 1), pp. 35-36. Sobre España (donde, en 1976, se creó la primera comunidad de usuarios de aguas subterráneas en el Delta de Llobregat, a la cual se han sumado otras, que hoy integran la Asociación Española de Usuarios de Aguas Subterráneas), ver Aldaya, Maite et al., El agua en España: bases para un pacto de futuro (Madrid, Fundación Botín, 2012), pp. 68-70; EmBID, Antonio, El Derecho de Aguas del siglo XXI, en Actas de Derecho de Aguas 2 (2012), pp. 90-91 y 94; y, LÓPEZ-GunN, Elena y RicA, Marta, La participación activa de los usuarios: la co-gestión como forma de gobernanza del agua subterránea, en LAS MISMAS (coordinadoras), Gestión colectiva del agua subterránea en España (Madrid, Fundación Botín, 2013), p. 32. En la misma línea, pero aplicado al modelo australiano, ver SARKer, Ashutosh et al., Managing groundwater as a common-pool resource: an australian case study, en Water Policy 11 (2009), pp. 605-612; y, Holley, Cameron y SinClaIR, Darren, Collaborative governance and adaptive management: (mis)applications to groundwater, salinity and run-off, en The Australasian Journal of Natural Resources Law and Policy 14 (2011) 1, pp. 59-65. En Chile, ver Muñoz, Jaime, Gestión de acuiferos. Disponibilidad técnica y jurídica de aguas subterráneas, en Revista de Derecho Administrativo Económico I (1999) 2, p. 323; Neumann, Christian, Aspectos generales, derechos y obligaciones en las organizaciones de usuarios de aguas, en Revista de Derecho Administrativo Económico III (2001) 2, pp. 597-598; ArÉVAlo, Gonzalo, cit. (n. 4), pp. 190-194; Donoso, Guillermo, cit. (n. 25), pp. 217-233; y, Vergara, Alejandro, Crisis, cit. (n. 21), p. 181.

30 Sobre las ventajas y límites de las fórmulas de autoorganización, aludiendo a experiencias concretas, ver Ostrom, Elinor, Comprender, cit. (n. 16), pp. 651-664; $\mathrm{y}$, LA MISMA, Collective action and the evolution of social normas, en Journal of Natural Resources Policy Research 6 (2014) 4, pp. 235-252. En idéntica dirección, en base a experiencias de España, ver Schlager, E. y López-Gunn, E., cit. (n. 2), pp. 44-48; y, López-Gunn, Elena y Rica, Marta, cit. (n. 29), pp. 15-33. Tomando evidencias empíricas de varios países, ver Mechlem, Kerstin, cit. (n. 29), pp. 29-31. 
de disminución de cantidad y calidad de sus recursos. Y, precisamente, cuando hay problemas de disponibilidad o agotamiento, la posibilidad de reunión, de gestión común y colectiva, deja de ser totalmente ajena para los usuarios de aguas subterráneas; se adquiere conciencia de la relevancia que pueden tener las organizaciones de usuarios, como una fórmula que permite compartir y asumir solidariamente los costos de la escasez ${ }^{31}$.

\section{ENTENDIENDO EL FRACASO DE LA GESTIÓN DE AGUAS SUBTERRÁNEAS: UNA RESPONSABILIDAD COMPARTIDA}

Las principales cuestiones que han obstaculizado la implementación y funcionamiento de las organizaciones de usuarios de aguas subterráneas son, a mi juicio, las siguientes:

\section{Cortapisas regulatorias: insuficiencia y carencia de rigurosidad nor-} mativa

Las respuestas legislativas deben tener en cuenta y hacerse cargo de las especificidades de las aguas subterráneas; ello, hasta ahora, no ha ocurrido satisfactoriamente ${ }^{32}$. Los autores del Código de 1981, aun después de la

${ }^{31}$ En esta línea, ver Ostrom, Elinor, Comprender, cit. (n. 16), p. 574. En el caso de Copiapó, se ha sostenido que las organizaciones de usuarios podrían cumplir un importante rol al enfrentar el sobreotorgamiento de derechos en la zona, a través de acuerdos entre sus titulares; hasta ahora, sin embargo, su actuación ha sido limitada. Ver Bitrán, Eduardo et al., Water management problems in the Copiapó basin, Chile: markets, severe scarcity and the regulator, en Water Policy 16 (2014), pp. 860-861.

${ }^{32}$ Desde hace muchos años se viene advirtiendo que el Código de 1981 está en deuda en materia de comunidades de aguas subterráneas. A estos efectos, pueden verse Peralta, Fernando, Aguas subterráneas, un recurso inexplorado y desconocido, en Derecho en la Región I (1993) 1, p. 46; y, ArÉvalo, Gonzalo, cit. (n. 4), pp. 185-187.

Esta tónica se da también en otros regímenes, en que, históricamente, las aguas subterráneas han sido desreguladas o absorbidas por la regulación creada para las superficiales. Así, respecto al caso australiano, ver CASSAR, Angela, A critical evaluation of existing legal regimes to the protection and management of groundwater, en Environmental and Planning Law Journal 17 (2000) 5, pp. 406-409. Sobre la situación norteamericana, ver GETCHES, David, Controlling groundwater use and quality: a fragmented system, en Natural Resources Lawyer 17 (1985) 4, pp. 623-625; SANDINO, David, cit. (n. 10), pp. 471-482; HedGes, John, Currents in California Water Law: the push to integrate groundwater and surface water management through the Courts, en Water Law Review 14 (2010-2011) 2, pp. 376-379; Thompson, Barton, Beyond connections: pursuing multidimensional conjunctive management, en Idaho Law Review 47 (2011), pp. 273-276; y, STEVENS, Jan, California's groundwater: a legally neglected resource, en Hastings West-Northwest Journal of Environmental Law and Policy 19 (2013) 1, pp. 4-10. Con relación a España, ver Llamas, M. Ramón et al., cit. (n. 
reforma efectuada el año 2005, creyeron que bastaba con la incorporación de las voces "subterráneas" y/o "acuífero" en la regulación de las organizaciones de usuarios para hacer inmediatamente operables las entidades colectivas en materia de aguas subterráneas. Claramente fue un equívoco, y prueba de ello es el escaso número de dichas entidades; aunque varios factores concurren a explicar este fracaso, las insuficientes y poco rigurosas disposiciones legales tienen gran influencia en el mismo.

Pese a que las directrices centrales deben estar en la ley, el Decreto No203, de 2014, dejó pasar una preciada oportunidad para contrarrestar la deuda regulatoria que se mantiene en este campo. A mayor abundamiento, este Reglamento introdujo elementos confusos y que podrían complicar más la gestión colectiva de las aguas subterráneas y su manejo conjunto con las superficiales.

a) Fijación en detalles literales menores y olvido de exigencias sustanciales. Considerando que todas las aguas que afluyen, superficial o subterráneamente, a una misma cuenca u hoya hidrográfica constituyen una unidad, no era necesario explicitar que las aguas subterráneas se encuentran bajo la jurisdicción de la junta de vigilancia organizada en la cuenca respectiva; ello se subentendía. Mayores detalles sí son necesarios respecto al funcionamiento de las juntas de vigilancia en materia de aguas subterráneas, a la participación de los usuarios en sus diversas instancias, y al estatuto jurídico de la entidad primaria o de base que se eligió para operar en este ámbito: comunidad de aguas (prescripciones especiales sí existen, por ejemplo, para las comunidades de obras de drenaje).

La integración de la gestión y regulación de aguas superficiales y subterráneas no debe asumirse como una homogenización de todas sus reglas ${ }^{33}$.

1), pp. 2570-2576; y, EmBiD, Antonio, A vueltas con la propiedad de las aguas. La situación de las aguas subterráneas a veinte años de la entrada en vigor de la Ley de Aguas de 1985. Algunas propuestas de modificación normativa, en Justicia Administrativa 1 (2006), p. 204, y, El MISMO, Organizaciones de usuarios y participación en la gestión del agua en el Derecho español: reflexiones generales y consideración de la reciente legislación peruana de aguas sobre estas cuestiones, en Urteaga, Patricia - Verona, Aarón (editores), Cinco años de la Ley de Recursos Hidricos en el Perú. Segundas Jornadas de Derecho de Aguas (Lima, Centro de Investigación, Capacitación y Asesoría Jurídica Departamento Académico de Derecho, Pontificia Universidad Católica del Perú, 2015), pp. 231-232. Para India, ver Cullet, Philippe, cit. (n. 1), pp. 55-65. Desde una óptica general, ver Llamas, M.R. y Martínez-Santos, P., cit. (n. 29), pp. 337 339; Lopez-Gunn, Elena y JaRvis, Todd, Groundwater governance and the Law of the Hidden Sea, en Water Policy 11 (2009), p. 743; Legislative Analyst's Office (LAO), cit. (n. 10), pp. 15-19; y, MeCHLEM, Kerstin, cit. (n. 29), pp. 36-38.

${ }^{33}$ En esta línea, en un análisis del caso australiano, ver CASSAR, Angela, cit. (n. 32), p. 407. 
Si bien algunas directrices de las organizaciones de usuarios de aguas superficiales pueden ser aplicables sin mayores ajustes a las subterráneas, en otras hipótesis la necesidad de soluciones propias, o al menos con ciertos matices, es notoria; algunos ejemplos:

i) Objeto de las comunidades de aguas. En la precisión de este tópico (art.186 CA, al cual se remite también el art.37 Decreto No203, de 2014), se establece que se trata de "tomar las aguas del caudal matriz, repartirlas entre los titulares de derechos, construir, explotar, conservar y mejorar las obras de captación, acueductos y otras que sean necesarias para mejorar su aprovechamiento". Lo que podría tener algún grado de aplicación en aguas subterráneas es lo relativo a obras, dispositivos e infraestructuras, aunque con la prevención de que ordinariamente no hay instalaciones comunes en este contexto. Pero la captación de aguas desde la fuente no la realiza una organización colectiva, sino que cada titular de derecho, por lo que no hay un reparto propiamente tal. Lo anterior, a menos que se conceda a estas expresiones ("captación" y "reparto") un sentido diverso, no material, estimando que las determinaciones que pueda adoptar la comunidad (sobre la base del acuerdo global definido a nivel de fuente por la junta de vigilancia respectiva) respecto a la oportunidad, forma y caudal que puede extraer cada uno de sus miembros, constituyen, indirectamente, extracción y reparto de aguas. Este matiz, que me parece correcto, debiera estar enunciado y explicado en una disposición legal.

ii) ¿Directorio como distribuidor de aguas subterráneas? El Reglamento, aludiendo al art.241 CA, menciona, con carácter no taxativo, los deberes y atribuciones del directorio de una comunidad de aguas subterráneas (art.38 Decreto No203, de 2014). Se incluyen una serie de conceptos jurídicos y técnicos indeterminados, cuyo sentido y alcance es difícil perfilar ("gestión integrada y sustentable del sector hidrogeológico de aprovechamiento común", "regular la explotación del sector hidrogeológico de aprovechamiento común", entre otros).

La primera atribución-deber que se considera es la de "distribuir las aguas del sector hidrogeológico de aprovechamiento común entre los comuneros a prorrata de sus derechos de aprovechamiento". Valgan para este supuesto los comentarios previos sobre el modo en que debiera entenderse la tarea de "distribución" que se encomienda a una organización conformada por titulares que tienen acceso directo al recurso, y que, por ende, no entrega materialmente aguas. La "distribución" sería de carácter indirecto, al decidir el directorio cuánta agua puede bombear cada usuario en un momento dado. El monitoreo, control y constante intercambio de información entre los comuneros y la comunidad, y entre ésta y la junta de vigilancia correspondiente, son fundamentales en este campo. 
iii) Juntas de vigilancia: ¿inclusión de las comunidades de aguas subterráneas? Aunque existen disposiciones legales aisladas que expresamente afirman que los derechos de aguas subterráneas pertenecen al espectro de actuación de las juntas de vigilancia, hay una multiplicidad de aspectos que quedaron desregulados, y cuya claridad se requiere para la incorporación y participación de una comunidad de esta índole en una junta de vigilancia ${ }^{34}$.

Como no hay experiencias prácticas al respecto, surgen interrogantes que la normativa no responde certeramente; por ejemplo, ¿cómo se concilian las sectorizaciones de acuíferos con la extensión de la cuenca a nivel superficial, que, salvo algunos ríos seccionados, es considerada y manejada como una unidad? ¿Rigen para los derechos de aguas subterráneas las mismas reglas de sus pares superficiales en cuanto a participación accionaria, quórum y votaciones? ¿Aplicación de sanción de privación de agua a titulares o comunidades de aguas subterráneas? ¿Puede una junta de vigilancia incorporar individualmente a los titulares de derechos de aguas subterráneas no organizados como comunidad?

iv) Extensión de las reglas de las aguas superficiales a las subterráneas. ¿Alternativas en los supuestos en que ello no es factible? El Decreto No203, de 2014, prescribe que las disposiciones del Código son aplicables a las comunidades de aguas subterráneas en lo que sean compatibles con su naturaleza; ya en algunos de los ejemplos revisados supra no lo son, ¿cómo se procede? ¿Debe estarse a lo que establezcan los estatutos correspondientes?

Si esta última fuese la opción, cabe precisar que los estatutos no suelen ser demasiado innovadores; la mayoría de estos textos son una transcripción de los artículos pertinentes del Código. Tampoco conviene ser innovador en este ámbito, pues la DGA, en el trámite de registro de la organización, efectúa una revisión que a veces excede sus funciones, obligando a los usuarios a efectuar cambios y rechazando la introducción de redacciones diferentes a las preestablecidas en la ley. ¿Qué alternativa queda? Claramente, en estas condiciones la explotación individual de aguas subterráneas se presenta como una vía bastante más sencilla, dado que no existen facilidades regulatorias para organizarse. $Y$, según reviso a continuación, hay más cortapisas normativas.

b) Desconexión entre juntas de vigilancia y comunidades de aguas subterráneas. Además de la ausencia de reglas apropiadas para las comunidades de aguas subterráneas y para las juntas de vigilancia en su relación con las primeras, hay una total desvinculación entre ambas organizaciones en el Decreto No203, de 2014. El aludido Reglamento ignora absolutamente a las juntas de vigilancia, no mencionándolas siquiera, olvidando que, por

${ }^{34}$ Coincidiendo con esta idea, ver Arévalo, Gonzalo, cit. (n. 4), pp.189-190. 
explícito mandato legal (art.263 CA), su jurisdicción alcanza a todas las aguas de la cuenca. Más allá del evidente descuido que esto denota, esta omisión se traduce en que las juntas de vigilancia no tienen participación en relevantes determinaciones respecto a las aguas subterráneas; por ejemplo: $i$ ) en los procesos de transformación de derechos provisionales en definitivos, en que sí se considera la notificación a la comunidad de aguas subterráneas organizada (art.32 Decreto No203, de 2014); ii) en el propio título en que se alude a las comunidades de aguas subterráneas, las juntas de vigilancia no aparecen como parte del modelo de administración y uso de las aguas; iii) ninguna intervención se reconoce a las comunidades de aguas subterráneas que pudieren existir en la zona sobre la que recaen solicitudes de cambio de puntos de captación y/o restitución y de fuente de abastecimiento; menos se considera la participación de la junta de vigilancia competente (arts.42 y 45 Decreto No203, de 2014); iv) la misma falencia se da en los procesos y autorizaciones relativos a la recarga artificial de acuíferos (arts.47 a 50 Decreto No203, de 2014).

Todo ello evidencia una especie de hidroesquizofrenia regulatoria, que se manifiesta tanto a nivel legal como reglamentario, pues:

$1^{\circ}$ Se busca fomentar la organización de comunidades de aguas subterráneas, pero se las excluye de importantes procesos, en que debieran tener un rol más activo, a través de informes que ayuden a la autoridad a adoptar decisiones más ajustadas a la realidad.

$2^{\circ} \mathrm{Se}$ mandata que las aguas superficiales y subterráneas se administren y gestionen conjuntamente ${ }^{35}$. Sin embargo, las juntas de vigilancia son olvidadas en el Reglamento de aguas subterráneas.

c) Confusiones y duplicidades terminológicas entre ley y reglamento. Pese a que el Decreto No203, de 2014, no efectuó modificaciones radicales respecto al contenido de la Resolución DGA No425, de 2007, sí incorpora algunas expresiones que alteran el lenguaje legislativo. El ejemplo más expresivo es el reemplazo, no uniforme ni total, de la voz "acuífero" (empleada, entre otros, en los arts.63, 65, 186, 263 No3 CA) por la fórmula "sector hidrogeológico de aprovechamiento común", solitaria y tímidamente enunciada en la legislación (art.65 CA), pero masificada en el Reglamento.

No obstante, esta masificación no es sistémica, lógica ni unificadora, pues en el Decreto No203, de 2014, surgen, una y otra vez, diversos conceptos para referirse a la fuente de aguas subterráneas. Se habla de "sector

35 A título referencial pueden citarse los arts.3, 22 y 263 CA y 20 e) del Decreto No203, de 2014. 
hidrogeológico de aprovechamiento común" (arts.20 c); 22; 25 inc.1 ${ }^{\circ}$; 29 a) y c); 30; 31; 32; 33 b); 34; 37; 38 a), b) y h); 42; 46; 48, 3a); 50; y, 54 g); de "acuífero" (arts.5 d); 13 d) y e); 18; 20 a); 25 inc. 2o; 27; 41; 47; 48 inc. $1^{\circ}$ y 3b); 49; y, 54 d), f) y g); de "fuente subterránea" (art.38 g); y, "zona acuífera" (art.54 e). Aun cuando el mayoritariamente usado es el primero, no se comprende por qué hay variaciones en las restantes disposiciones mencionadas. Éste no es un tema baladí o de mero alcance literal. El Reglamento incluye la noción de división de las fuentes hídricas subterráneas; y ello genera relevantes implicancias para la gestión del recurso, complejizando la implementación y funcionamiento de instancias colectivas en este ámbito.

2. Trabas administrativo-regulatorias: complicidad entre prácticas de la $D G A$ y la normativa

Hay dificultades que provienen de una mezcla de prácticas administrativas (de la DGA) y prescripciones legales y reglamentarias que introducen confusión y distorsiones en la gestión colectiva de aguas subterráneas; a saber:

a) Sectorización de acuíferos. El Reglamento define sector hidrogeológico de aprovechamiento común como el acuífero o parte del mismo que presenta características hidrológicas espacio-temporales que posibilitan su delimitación para fines de evaluación o gestión independiente (art.54 g) Decreto No203, de 2014). Esta conceptualización supone una fragmentación de las fuentes de aguas subterráneas, sobre lo cual pueden formularse varios comentarios:

i) ¿Es apropiada la denominación elegida? Sumado a la extensión de la expresión escogida, ella no es adecuada si se analiza el contexto y la finalidad que se supone tener. Particular atención merece la frase "de aprovechamiento común"; si se trata de distinguir, escindir e independizar tramos o sectores de un acuífero, ¿es coherente aludir a lo "común"? Es obvio que todos los titulares de derechos de aprovechamiento con puntos de captación en un sector determinado comparten tal calidad y esa área de la fuente subterránea con sus pares; ahí estaría lo común entre ellos. Pero todos los usuarios de una misma fuente (un río o un acuífero, que pueden estar o no divididos) realizan un aprovechamiento común. Entonces, para simplificar el concepto, habría bastado con la noción "sector hidrogeológico" o simplemente "sector", ya que su naturaleza resulta lógica al hablarse de un acuífero.

ii) Necesidad de estudios completos sobre el estado y condiciones de las aguas y fuentes subterráneas. La determinación de la concurrencia de las características que justificarían la sectorización normalmente se enfrenta 
con un precario conocimiento de los acuíferos y sus límites, dando lugar a interpretaciones conflictivas ${ }^{36}$. ¿Contamos con un nivel de información apropiado? ¿La DGA tiene un mapeo actualizado de todos los acuíferos del territorio nacional?

No disponiendo de antecedentes para dar una respuesta certera a estas interrogantes, al menos puede señalarse que un avance se refleja en el Atlas del Agua, recientemente publicado por el Ministerio de Obras Públicas y la DGA. Allí se afirma que, hasta el año 2015, la DGA ha delimitado 137 acuíferos, distinguiéndose en ellos 375 sectores hidrogeológicos de aprovechamiento común ${ }^{37}$. La sectorización, entonces, se está volviendo una práctica generalizada.

iii) ¿Quién y cómo se efectúa la sectorización? Es importante definir a quién corresponde la tarea de aprobar y formalizar (si hay un acto o declaración en este sentido) la división de un acuífero en uno o más sectores hidrogeológicos de aprovechamiento común.

Dado que se trata de otro tema desregulado, no cabe más que observar la práctica, que tampoco es clara. Si bien la DGA es la autoridad que se ha encargado de este cometido, no se conoce bien cómo y bajo qué supuestos y procedimientos se materializa. Al parecer, el origen de esta separación o división administrativa suele provenir de uno o más estudios técnicos, usualmente elaborados por ingenieros o consultores particulares, que luego, al ser incluidos o citados en pronunciamientos del citado Servicio, adquieren casi un sello de veracidad irrefutable.

Vuelve a surgir la duda de si la DGA posee información detallada, no sustentada únicamente en informes aislados, para ejecutar la sectorización. ¿̨e da en estas materias, como ocurre en otros sitios, una adecuada colaboración entre la DGA y el Servicio Nacional de Geología y Minería (SERNAGEOMIN)?38

Hasta ahora, el ejemplo paradigmático de esta oscura práctica administrativa es el acuífero de Copiapó, que ha sido administrativamente dividido en seis sectores hidrogeológicos. Así lo ha venido entendiendo y mani-

${ }^{36}$ Efectuando este análisis para el puntual caso de California, ver KIPARSKY, Michael et al., cit. (n. 1), p. 14.

37 Ministerio de Obras Públicas y Dirección General de Aguas, cit. (n. 20), p. 70 .

${ }^{38}$ En España, por ejemplo, existe una actuación mancomunada de la autoridad del agua y del Servicio Hidrogeológico Minero, entidad que ha mapeado todas las masas de aguas subterráneas del territorio. Lo mismo ocurre en Estados Unidos, donde el U.S. Geological Survey ha cumplido un rol fundamental en este campo. Constatando esto último, ver Osтrom, Elinor, Comprender, cit. (n. 16), pp. 645646; y, Legislative Analyst's Office (LAO), cit. (n. 10), p. 11. 
festando la DGA en diversos actos administrativos, dictando, separada y autónomamente, declaraciones de área de restricción o zona de prohibición para uno u otro sector. Ello, pese a que la interconexión hidrológica entre ellos sería evidente, según lo han acreditado algunos estudios técnicos ${ }^{39}$; asimismo, la propia Contraloría ha cuestionado esta división, dejando de manifiesto la necesidad de alumbrar y transparentar este tema ${ }^{40}$.

iv) ¿Finalidad acorde a la gestión conjunta o integrada de aguas? La sectorización de un acuífero tiene por objeto permitir la "evaluación" y "gestión" independiente de cada uno de sus tramos, dado que presentarían características hidrológicas que justificarían tal escisión. Las implicancias no son menores, pues se posibilita no sólo que cada sector se analice separadamente, sino que también se maneje independientemente de los sectores contiguos. Por ende, estamos ante una excepción a una regla general acentuada en nuestro modelo: la gestión de las aguas de una fuente por una única organización de usuarios ${ }^{41}$.

Retomando el caso de Copiapó, tenemos que la primera comunidad de aguas subterráneas formalizada en Chile (Copiapó-Piedra Colgada; Piedra Colgada-Desembocadura) ejerce jurisdicción en los sectores 5 y 6 de este acuífero; luego, para cada uno de los primeros cuatro tramos, se encuentran en proceso de formalización las respectivas comunidades (en la mayoría resta el registro ante la DGA). Por lo tanto, existirán en esa zona cinco comunidades de aguas subterráneas, distintas y desvinculadas. Sin perjuicio que la división en unidades más pequeñas podría facilitar, desde un punto de vista administrativo, la gestión de ciertos acuíferos, lo que en todo caso cabría acreditar y sustentar con información técnica rigurosa, esta multiplicidad de comunidades no se ajusta a la idea de gestión conjunta e integrada de las aguas; y ello es especialmente preocupante en un acuífero como el de Copiapó, que tiene evidentes problemas de sobreotorgamiento, sobreexplotación y calidad del recurso ${ }^{42}$.

Adicionalmente, revisando los preceptos del Reglamento, la "gestión" independiente de cada sector debe entenderse en un sentido amplio, pues no se trata sólo de administración y organizaciones de usuarios autónomas. La disponibilidad de aguas para el otorgamiento de nuevos derechos, por

39 En esta línea, ver Bitrán, Eduardo et al., cit. (n. 31), p. 848.

40 Con fecha 23 de abril de 2014, la CGR emitió el informe final No27, de 2013, sobre auditoría en la DGA, practicada en las regiones de Antofagasta, Atacama, Coquimbo y Valparaíso, respecto al período comprendido entre enero de 2008 y diciembre de 2012. Allí se advirtió la carencia de fundamentos técnicos que avalen la división de la cuenca del río Copiapó en sectores acuíferos independientes.

${ }^{41}$ Ver, particularmente, arts.3, 263, 266 y 272 CA.

${ }^{42}$ En esta dirección, ver Donoso, Guillermo, cit. (n. 25), p. 229. 
ejemplo, se definiría también separada y singularmente para cada sector (arts.20 c) y d), 22 inc. final y 25 Decreto No203, de 2014). Consecuentemente, ¿la obligación de evitar el perjuicio a derechos de terceros se reducirá a los límites del respectivo sector? Ello sólo podría ser procedente ante una desconexión total entre las distintas partes de un acuífero, cuestión que no sería habitual y, además, es de difícil precisión ${ }^{43}$.

v) ¿Se consideró la excepcionalidad de los seccionamientos de fuentes superficiales y los complejos efectos que algunos de ellos han ocasionado? Podría pensarse que la sectorización de acuíferos, que aparte de una solitaria mención en el art.65 CA no posee otra base explícita en la ley, tiene su origen en exitosas experiencias afines en materia de aguas superficiales. No obstante, en este último ámbito el seccionamiento ha estado lejos de producir alentadores ejemplos de gestión del recurso. Adicionalmente, debe reafirmarse un punto esencial para el análisis: el seccionamiento está establecido en nuestro Derecho de Aguas como una situación excepcional, pues la regla general es que cada cuenca hidrográfica sea administrada por una misma junta de vigilancia (art.263 CA) ${ }^{44}$.

El seccionamiento y la administración separada se admiten en dos supuestos: para casos previos al Código de 1981, cuando se trate de corrientes consideradas distintas para los efectos de distribución; y, en aquellas secciones en que las aguas se reparten de manera independiente de las secciones vecinas (art.264 CA). En realidad, ambos supuestos pueden unificarse en uno sólo: la legislación permite que las aguas superficiales de una misma cuenca se gestionen por dos o más juntas de vigilancia cuando tales aguas se distribuyen desvinculada y autónomamente en diferentes secciones ${ }^{45}$.

No son muchos los ríos seccionados y gestionados por más de una junta de vigilancia ${ }^{46}$; $y$ hay cuencas que, aun estando divididas en tramos,

${ }^{43}$ Paradojalmente, así parece concebirlo también el propio Reglamento, al precisar, entre las causas que justifican la declaración de un área de restricción, que el aumento de extracciones en un sector puede afectar la disponibilidad sustentable de otro (art.30 e) Decreto No203, de 2014); ¿̨no es esto acaso un reconocimiento de la idea opuesta al seccionamiento, la interconexión acuífera?

${ }^{44}$ Y ello era regulado en idéntico modo en los Códigos anteriores: arts.159 CA 1981 y 165 CA 1967.

45 Destacando la excepcionalidad del seccionamiento y su procedencia únicamente en la referida hipótesis, ver Arévalo, Gonzalo, cit. (n. 4), pp. 188-189 y Vergara, Alejandro, Autogobierno, cit. (n. 13), p. 172. Ratificando este criterio en sede jurisprudencial, ver Corte de Apelaciones de San Miguel, Reyes Zapata, Jorge, Rol No 2052-2016, 14 de abril de 2016.

${ }^{46}$ Entre ellos pueden mencionarse los casos del río Aconcagua, en que existen 4 secciones y 4 juntas de vigilancia (la correspondiente a la cuarta sección tendría pendiente el registro en la DGA); y el río Maipo, en que sólo se ha formalizado 
distritos o secciones, son administradas igualmente por una única organización $^{47}$, confirmando la premisa general. Las cuencas seccionadas en que opera más de una junta de vigilancia han estado constantemente asociadas a conflictos que denotan la carencia de un reparto justo y equitativo de las aguas; particularmente en épocas de escasez, cada vez más recurrentes, los usuarios de las primeras secciones tienden a aprovechar gran parte de los caudales existentes, dejando sedientas a las secciones inferiores ${ }^{48}$.

Por lo tanto, en un contexto en que la sequía ha dejado de ser un fenómeno extraordinario, puede preverse un resultado poco auspicioso y pacífico en los acuíferos en que se implemente y haga efectiva la referida sectorización y gestión independiente de las aguas. Sobre todo considerando que, a diferencia de los seccionamientos superficiales, la sectorización subterránea no fue regulada ni está siendo aplicada como una fórmula excepcional; al contrario, los acuíferos unitarios serían la excepción.

b) Trabas/demoras en la DGA en el registro de organizaciones de usuarios. La conformación de las comunidades de aguas subterráneas, ya sea convencional o judicialmente, es bastante lenta (aunque la vía convencional es más expedita, no es la más recurrente, por la dificultad de reunir la voluntad y firma de todos los titulares de derechos involucrados). En sede judicial, una sentencia declara la existencia y aprueba los estatutos de la comunidad, tras lo cual los usuarios deben enfrentar una etapa cuya

totalmente la Junta de Vigilancia de la primera sección, pero se encuentran en tramitación las correspondientes a secciones inferiores. Sobre este punto, se enfatiza que "En nuestro país, hay algunas fuentes cuya situación debiera revisarse, pues presentan secciones administradas por organizaciones independientes y distintas, pese a que, en la práctica, la distribución de una surte inevitablemente efectos en las restantes. Ante tales circunstancias, no sería prudente y legítimo conservar los seccionamientos, los cuales, contrariamente, deberían suprimirse en todos aquellos casos en que el manejo o reparto separado de las aguas de una cuenca produzca injusticias y desequilibrios" (Vergara, Alejandro, Autogobierno, cit. (n. 13), p. 172).

${ }^{47}$ Así, por ejemplo, la Junta de Vigilancia del Río Copiapó tiene jurisdicción sobre los 9 distritos en que se encuentra dividida la fuente; y la Junta de Vigilancia de la Cuenca del Río Huasco y sus Afluentes actúa sobre los 4 tramos que conforman la cuenca.

${ }^{48}$ Recurrentes han sido estas circunstancias en el río Aconcagua, donde sus juntas de vigilancia periódicamente se enfrentan a desacuerdos en la redistribución de las aguas tras declaraciones de zona de escasez. La DGA ha adoptado una posición más bien pasiva, incluso ante solicitudes concretas de intervención por parte de los usuarios. La respuesta jurisprudencial tampoco ha sido favorable a la equidad en el uso de las aguas en este escenario; ver Corte Suprema, Junta de Vigilancia de la Tercera Sección del Río Aconcagua con Junta de Vigilancia de la Primera Sección del Río Aconcagua, Rol No 2014-2014, 25 de marzo de 2014. 
duración y resultados son inciertos: la solicitud del registro de la organización ante la DGA (art.196 CA).

En el marco de este registro, donde el rol de la autoridad es verificar que la comunidad se haya constituido en conformidad a la ley, la DGA suele adoptar una posición excesiva en cuanto a la extensión de sus potestades, exigiendo, luego de haber revisado los antecedentes por un largo período (indeterminado en su extensión), modificaciones en los estatutos que fueron aprobados por los titulares de derechos (organización convencional), o bien, por éstos y el juez (organización judicial) ${ }^{49}$. Mientras esos cambios no se materialicen, el registro queda en suspenso; y aun cuando la organización pueda estar funcionando, la DGA la desconoce como tal, pues, en base al inc. final del art.196 CA, estima que ella carece de personalidad jurídica.

Sin desconocer el tenor literal de la mencionada disposición, no puede dejar de advertirse lo extrema de esta postura y la improcedencia de hacer depender el surgimiento de la personalidad jurídica de las organizaciones de usuarios de una resolución de la DGA, respecto a la cual, además, no hay plazo vinculante que la obligue a actuar con celeridad y eficiencia. ¿Qué puede hacer la organización en el tiempo intermedio? ¿Abdicar sus deberes y funciones a la espera de un pronunciamiento que puede tardar años en producirse? ${ }^{50}$

La materialización de la inclusión de los derechos de aguas subterráneas en las juntas de vigilancia requerirá una reforma de sus estatutos. Dicha reforma debe ser registrada en la DGA, por lo que, si bien la organización está previamente formalizada, también son previsibles las mencionadas dilaciones.

Ciertamente, estas circunstancias desincentivan la implementación de las fórmulas de gestión colectiva y conjunta de aguas subterráneas.

\section{Externalidades y obstáculos provenientes de los propios usuarios: falta}

49 Sobre los inconvenientes prácticos y jurídicos que esta actitud de la DGA conlleva, ver MuÑoz, Gonzalo, El registro de las organizaciones de usuarios de aguas por la Dirección General de Aguas, en Revista de Derecho Administrativo Económico 2 (2003), pp. 305-308.

50 "...las disposiciones relativas a organizaciones de usuarios provienen de textos decimonónicos, cuyo tenor, sentido y contexto son muy distintos a la ideología central del Código de 1981, en el cual hoy se encuentran inmersas. Concretamente, debieran impulsarse modificaciones tendientes a garantizar reales posibilidades de autorregulación de las organizaciones y limitar expresamente la actividad y efectos del registro de las mismas en el Catastro Público de Aguas de la DGA, cuidando, sobre todo en este último punto, guardar coherencia con los actuales parámetros en materia de autonomía y obtención de personalidad jurídica de los grupos intermedios de la sociedad." (Vergara, Alejandro, Autogobierno, cit. (n. 13), p. 170). 
de comprensión del sistema, recursos, interés y compromiso. Sumándose a las dificultades regulatorias y de práctica administrativa aludidas, deben incluirse algunos factores adicionales que explican el fracaso comentado:

a) Conocimiento limitado. La dinámica y real estado de las aguas subterráneas son temas en que, pese a los avances de los últimos años, todavía existe un grado de desconocimiento e incerteza importante ${ }^{51}$. Quizás en Chile ello se ha acentuado por la carencia de un diálogo interdisciplinario más fluido. Sólo de ese modo, combinando, al menos, elementos legales, ambientales, sociales, económicos e hidrológicos, se puede construir e implementar un sistema de uso sustentable de este recurso ${ }^{52}$; el monitoreo, la información y el conocimiento son cruciales para la gestión efectiva de las aguas subterráneas ${ }^{53}$.

La falta de claridad y el escaso, casi nulo, interés jurídico doctrinal sobre las aguas subterráneas, se han traducido en una sesgada y pobre comprensión de su situación. Si a ello añadimos el hecho físico de su invisibilidad, no resulta difícil comprender por qué ha sido tan compleja su introducción al sistema de gestión colectiva que la ley y el reglamento, aunque sea superficialmente, establecen para ellas.

b) Insuficiencia de recursos. La formalización y puesta en práctica de las comunidades de aguas subterráneas y la extensión de la actividad de las juntas de vigilancia a su respecto, requieren recursos materiales, económicos y humanos. En principio, para reunir información y tener una panorámica general de los derechos que existen en las respectivas áreas jurisdiccionales, y del estado cuantitativo y cualitativo del recurso; y, luego, para poder administrar, gestionar y fiscalizar adecuadamente, de modo que las aguas se usen en conformidad a los títulos, a la disponibilidad de cada temporada y a los acuerdos adoptados ${ }^{54}$.

Los presupuestos de las organizaciones de usuarios, que se autofinancian, usualmente son limitados; tampoco disponen siempre de funcionarios

${ }^{51}$ Como advierte Ostrom, una causa fundamental de la incertidumbre en el manejo colectivo de los recursos de uso común es la falta de conocimiento; la estructura del sistema de recursos debe conocerse, $\mathrm{y}$, en el caso de las aguas subterráneas, por sus especificidades, requiere una inversión especializada mayor en el trabajo de ingenieros y geólogos. Ver Ostrom, Elinor, El gobierno, cit. (n. 2), pp. 82-83.

${ }^{52}$ En esta línea ver Gorelick, Steven y ZHENG, Chunmiao, cit. (n.1), pp. 30453046.

53 En esa dirección, ver Kiparsky, Michael et al., cit. (n. 1), p. 25; y, Holley, Cameron y Sinclair, Darren, Deliberative, cit. (n. 29), pp. 64-69.

${ }^{54}$ Como precisan Gorelick y Zheng, una necesidad constante en la gestión de las aguas subterráneas es disponer de herramientas de modelación integradoras y eficientes, que permitan enfrentar las amenazas a su calidad y cantidad. Ver Gorelick, Steven y ZHENG, Chunmiao, cit. (n. 1), p. 3044. 
capacitados sobre materias que, en gran medida, son poco conocidas. Así, la tarea de gestionar las aguas subterráneas, aun cuando les corresponde legalmente, se complica también por este tipo de problemas.

c) Carencia de real interés y compromiso. No todas las causas del fracaso de la gestión colectiva de aguas subterráneas son externas a los titulares de derechos. Para ellos puede resultar más cómodo (por la individualidad, libertad y ausencia de control directo) ejercer sus derechos en forma aisla$\mathrm{da}$, sin que sea necesario participar en una comunidad. Igualmente, a las comunidades de aguas subterráneas organizadas y a los usuarios individualmente considerados, tampoco les resulta llamativa la idea de incorporarse a la junta de vigilancia de la cuenca, pues ello se traduce en una especie de pérdida de poder; y lo más probable es que las juntas tampoco tengan real intención de hacerse cargo de las aguas subterráneas.

De este modo, surge un círculo de desconfianza, desinterés y falta de compromiso frente a las aguas subterráneas, que ha sido complejo desarticular, y que impide el desarrollo de instancias colectivas de gestión de este recurso.

\section{El DECISIVO ROL DE LAS JUNTAS DE VIGILANCIA EN LA GESTIÓN CONJUNTA Y COLECTIVA DE LAS AGUAS}

Tal como observa Thompson, la visibilidad parece ser un factor clave en la gestión de los recursos; ello explicaría por qué en recursos invisibles (como las aguas subterráneas) dicha tarea es más compleja que en el caso de los visibles (aguas superficiales y bosques, por ejemplo). En ese escenario, explica el autor, la gestión de las aguas subterráneas comprendería dos pasos. El primero consiste en establecer tres relevantes conexiones: con las aguas superficiales, con los ecosistemas dependientes y con la planificación territorial, recarga y calidad de las mismas aguas subterráneas; luego, en segundo orden, procede construir un sistema flexible, dinámico y adaptable, para cuyo logro es necesario un complemento entre herramientas públicas o estatales y de mercado ${ }^{55}$.

Si aplicáramos estas ideas al caso chileno, habría que señalar que estamos recién en vías de implementación de la primera de las conexiones (aguas subterráneas y superficiales), lo cual no ha sido simple. En esta tarea de alcanzar una gestión conjunta y colectiva de las aguas ${ }^{56}$, el papel de las juntas de vigilancia es fundamental, según se explica a continuación.

55 Thompson, Barton, cit. (n. 32), pp. 279-323.

${ }^{56}$ Especialmente tratándose de esta primera conexión que se alude supra, es preferible hablar de gestión conjunta o integrada de aguas, concepto más específico, y no de gestión integrada de cuencas o de recursos hídricos; estas últimas nociones 


\section{Predominio de la unidad de la cuenca y superación de las sectorizaciones}

Sin perjuicio de considerar necesaria y conveniente la formalización de comunidades de aguas subterráneas, como organizaciones de base, el rol central e integrador lo detentan las juntas de vigilancia, especialmente dadas las disgregaciones que produce la sectorización de acuíferos. Una vez que se organicen más comunidades de aguas subterráneas, habrá que enfrentar un nuevo reto: en un mismo acuífero podrán existir dos o más organizaciones de este tipo, actuando separada e indistintamente. Aun admitiendo que puedan concurrir condiciones que aconsejan esta separación en ciertos acuíferos, el imperativo de gestión conjunta de las aguas de una misma cuenca, como unidad, no desaparece; al contrario, se acentúa en estas circunstancias ${ }^{57}$.

¿Cómo lograr tal imperativo si en un acuífero se organizan, por ejemplo, cinco o seis comunidades de aguas subterráneas autónomas? No creo que deba recurrirse a la creación de una nueva figura para estos efectos; la solución, aunque con insuficiencias regulatorias que cabría superar, ya está contemplada: a la junta de vigilancia de la respectiva cuenca le corresponde integrar a todas y cada una de esas comunidades y gestionar, conjuntamente, aguas superficiales y subterráneas ${ }^{58}$. La eventual existencia de más de una junta de vigilancia en los ríos seccionados, conllevará dificultades adicionales y no fáciles de conciliar ${ }^{59}$. Lo mismo sucederá al tratar de acomodar la jurisdicción de la junta de vigilancia a la extensión territorial y características del acuífero o sectores hidrogeológicos de aprovechamiento común; la fragmentación, en uno u otro caso (seccionamiento superficial y sectorización subterránea), dificulta significativamente la coordinación y acción colectiva, requiriéndose ajustes legales que orienten en este sentido ${ }^{60}$.

han sido criticadas por su ambigüedad, imprecisión, amplitud y dificultad de concreción práctica. Sobre ello, ver BISWAS, Asit, Integrated water resources management: a reassessment, en Water International 29 (2004) 2, pp. 248-256; GRIGG, Neil, Integrated water resources management: balancing views and improving practice, en Water International 33 (2008) 3, pp. 279-291; GIORDANO, Mark y SHAH, Tushaar, From IWRM back to integrated resources management, en International Journal of Water Resources Development 30 (2014) 3, pp. 364-374; Rojas, Christian, Autogestión, cit. (n. 13), pp. 125-126; y, ORGANISATION FOR ECONOMIC COOPERATION AND DEVELOPMENT (OECD), cit. (n. 10), p. 3. 135.

${ }^{57}$ Con esta orientación, ver Rojas, Christian, Autogestión, cit. (n. 13) pp. 134-

${ }^{58}$ En esta dirección, ver Neumann, Christian, cit. (n. 29), pp. 597-598.

59 En este sentido, ver Donoso, Guillermo, cit. (n. 25), pp. 229-230.

${ }^{60}$ En general, el estatuto jurídico de las juntas de vigilancia debe ser refaccionado, pues la mayor densidad normativa existe respecto a las comunidades de aguas, lo cual se aplica supletoriamente a las juntas de vigilancia, en circunstancias que su 


\section{Coordinación global en el aprovechamiento de las aguas}

Son las juntas de vigilancia las que deben determinar, tomando en cuenta la interrelación entre aguas superficiales y subterráneas, los volúmenes que pueden captar o extraer todos sus miembros, incluidos los usuarios subterráneos. Ello no obsta a que luego, en el marco de tal determinación global, las comunidades puedan acordar fórmulas internas de uso del recurso para sus miembros ${ }^{61}$.

Como no hay reparto o entrega material de los caudales correspondientes a los titulares de derechos de aguas subterráneas, debe existir un control permanente de las extracciones realizadas, con una cercana conexión y colaboración entre la junta de vigilancia y la comunidad respectiva.

La falta de formalización de las comunidades de aguas subterráneas no puede ser impedimento para la gestión colectiva y conjunta de los derechos de aguas de una cuenca, por lo que, independientemente de ello, la junta tendría que asumir su rol, promoviendo, paralelamente, la formalización de las comunidades para que cumplan las tareas de administración, control y manejo interno que les corresponderían ${ }^{62}$. En el período intermedio, la junta de vigilancia debería adoptar sus acuerdos de distribución y uso para aguas superficiales y subterráneas, y asumir directamente el rol de fiscalización en el uso de estas últimas. Ciertamente es un proceso complejo y engorroso, que implica una carga importante para las juntas de vigilancia, por lo que las reglas debieran contemplar cierta gradualidad y flexibilidad en el cumplimiento de estos fines.

La integración de la totalidad de los aprovechamientos de aguas de una cuenca en la correspondiente junta de vigilancia no es una permisividad reconocida por el ordenamiento jurídico; es una obligación ${ }^{63}$. Por ende, mientras ello no se materialice, y pese a las trabas y cortapisas que la misma ley contiene, hay un incumplimiento generalizado de sus disposiciones.

entidad y atribuciones son muy distintas. En este dirección, ver RoJAS, Christian, Autogestión, cit. (n. 13) p. 132.

${ }^{61}$ Afirmando que la única vía para maximizar los beneficios de los recursos hídricos es usar coordinadamente las aguas superficiales y subterráneas, ver GETCHES, David, cit. (n. 32), p. 625. En similares términos, ver NANNI, cit. (n. 29), p. 634. Postulando la relevancia de que "un" órgano tenga responsabilidad respecto a la gestión conjunta de ambos recursos, ver Cullet, Philippe, cit. (n. 1), p. 70.

${ }^{62}$ Debe reformularse el actual estatuto legal y reglamentario de estas comunidades, de modo de focalizar su actuación en las funciones que efectivamente debieran cumplir, de acuerdo a su naturaleza y a la especial vinculación que debe tener la junta de vigilancia respectiva con estas entidades de base y con el aprovechamiento de las aguas subterráneas de la cuenca.

${ }^{63}$ En este sentido, ver Rojas, Christian, Autogestión, cit. (n. 13) p. 151; y, EL MISMO, La categoría, cit. (n. 11), p. 191. 


\section{Aporte a la construcción de un Derecho y gestión de aguas adaptable}

La gestión dirigida en cada cuenca por la junta de vigilancia respectiva es esencial para manejar las aguas subterráneas promoviendo, desde una instancia local y participativa, medidas preventivas que permitan cuidar su calidad y configurarlas como una reserva frente a la sequía, disminuyendo la vulnerabilidad de los sistemas hídricos a amenazas cada vez más recurrentes.

Ésta es la vía hacia la cual están transitando algunos países que han enfrentado condiciones hídricas extremas en los últimos años, develando el complejo desafío de contar con un Derecho y gestión de aguas "adaptable" a escenarios variables, en que, producto del cambio climático, las sequías e inundaciones han dejado de ser fenómenos aislados y extraordinarios ${ }^{64}$. Chile experimenta actualmente una situación que ha sido catalogada como "megasequía" 55 , por lo que es momento oportuno para revisar el rumbo de la regulación y políticas públicas en este campo.

\section{Conclusiones}

1. Desde los orígenes de nuestra regulación de aguas, las organizaciones de usuarios son contempladas como las entidades colectivas que, conformadas por los propios titulares de derechos de aprovechamiento en una misma fuente natural $\mathrm{u}$ obra artificial, gestionan y distribuyen el agua a sus miembros.

2. Éste ha sido el modelo tradicional de uso de las aguas superficiales; pero las aguas subterráneas, pese a ser igualmente bienes comunes, y a los intentos legislativos y reglamentarios dirigidos al efecto, son aprovechadas

${ }^{64}$ A este respecto, pueden verse interesantes análisis sobre el caso norteamericano, en Neuman, Janet, Drought proofing Water Law, en Water Law Review 7 (20032004), pp. 105-110; California Energy Commission y University of California, SANTA CRUZ, Climate change and water supply security: reconfiguring groundwater management to reduce drought vulnerability (Santa Cruz, California Energy Commission-California Natural Resources Agency, 2012), 72 pp.; y, LANGRIDGE, Ruth, Drought and groundwater: legal hurdles to establishing groundwater drought reserves in California, en University of California, Davis Law Review 36 (2012) 1, pp. 91-113, y, LA MISMA, Confronting drought: water supply planning and the establishement of a strategic groundwater reserve, en Water Law Review 12 (2009) 2, pp. 314-318. Con relación a España, ver Llamas, M. Ramón et al., cit. (n. 1), pp. 2572-2576. Desde la perspectiva australiana, ver GodDEn, Lee y KunG, Anthony, Water Law and planning frameworks under climate change variability: systemic and adaptive management of flood risk, en Water Resources Management 25 (2011), pp. 4051-4068. En una óptica general, ver Llamas, M.R. y Martínez-Santos, P., cit. (n. 29), pp. 339-340; y, Nanni, Marcella, cit. (n. 29), pp. 635-638.

${ }^{65}$ Centro de Ciencia del Clima y la Resiliencia (CR)2, La megasequía 20102015: una lección para el futuro (Santiago (CR)2, 2015), pp. 2 y 4-5. 
individual y aisladamente, constreñidas a las obras de captación de cada titular.

3. En el año 2005, se introdujeron al Código de Aguas una serie de modificaciones que explicitaron que las aguas subterráneas debían incorporarse al sistema de gestión colectiva. Ello, a través de la formalización de comunidades de aguas subterráneas y de la incorporación de estos aprovechamientos a la jurisdicción de las juntas de vigilancia.

4. Habiendo transcurrido más de diez años desde la inclusión de estas modificaciones legales, puede constatarse que la implementación de las fórmulas de gestión colectiva y conjunta de aguas subterráneas y superficiales ha fracasado. A ello han contribuido obstáculos regulatorios, de práctica administrativa, el desinterés de los usuarios y otros derivados de la propia realidad, todavía no cabalmente conocida, de las aguas subterráneas.

5. En este contexto, queda en evidencia que el vigente modelo de gestión de aguas requiere ajustes, tarea en que debiesen considerarse algunos propósitos sustanciales: a) revisar y reconstruir el estatuto de las comunidades de aguas subterráneas, poniendo especial atención en las funciones que efectivamente debieran cumplir, de acuerdo a su naturaleza y vinculación con las juntas de vigilancia; $\mathrm{y}, b$ ) potenciar el fundamental rol que corresponde a las juntas de vigilancia en la gestión colectiva y conjunta de aguas superficiales y subterráneas. Estas entidades son las que permiten imponer la directriz de unidad de la cuenca y superar los complejos efectos que puede acarrear la sectorización de acuíferos; impulsar la coordinación global en los aprovechamientos de aguas de dicha cuenca; y contribuir, de un modo participativo y localizado, a la configuración de un Derecho y gestión de aguas adaptable a escenarios cada vez más variables.

\section{BiBLIOGRAFÍA}

Aldaya, Maite, De Stefano, Lucía y Llamas, M. Ramón, El agua en España: bases para un pacto de futuro (Madrid, Fundación Botín, 2012), 91 pp.

Arévalo, Gonzalo, Comunidades de aguas subterráneas: dificultades en su organización y ejercicio, en Actas de Derecho de Aguas 3 (2013), pp. 185-194.

BISWAS, Asit, Integrated water resources management: a reassessment, en Water International 29 (2004) 2, pp. 248-256.

Bitrán, Eduardo, Rivera, Pedro y Villena, Marcelo, Water management problems in the Copiapo basin, Chile: markets, severe scarcity and the regulator, en Water Policy 16 (2014), pp. 844-863.

California Energy Commission y University of California, Santa Cruz, Climate change and water supply security: reconfiguring groundwater management to reduce drought vulnerability (Santa Cruz, California Energy Commission-California Natural Resources Agency, 2012), 72 pp.

CARrasco, Edesio, Comentarios al nuevo régimen de aguas subterráneas a partir de la 
reforma al Código de Aguas de 2005, en Revista de Derecho Universidad Católica del Norte 14 (2007) 2, pp. 53-80.

CASSAR, Angela, A critical evaluation of existing legal regimes to the protection and management of groundwater, en Environmental and Planning Law Journal 17 (2000) 5, pp. 406-425.

Centro de Ciencia del Clima y la Resiliencia (CR)2, La megasequía 2010-2015: una lección para el futuro (Santiago, (CR)2, 2015), 26 pp.

Cullet, Philippe, Groundwater Law in India, en Journal of Environmental Law 26 (2014), pp. 55-81.

Donoso, Guillermo, Integrated water management in Chile, en MarTínez-SANTOS, Pedro - Aldaya, Maite - Llamas, M. Ramón (editores), Integrated water resources management in the 21st century: revisiting the paradigm (Londres, CRC Press/ Balkema, 2014), pp. 217-233.

EMBID, Antonio, A vueltas con la propiedad de las aguas. La situación de las aguas subterráneas a veinte años de la entrada en vigor de la Ley de Aguas de 1985. Algunas propuestas de modificación normativa, en Justicia Administrativa 1 (2006), pp. 183-206.

Embid, Antonio, El Derecho de Aguas del siglo XXI, en Actas de Derecho de Aguas 2 (2012), pp. 79-103.

EmBiD, Antonio, El Acuerdo sobre el sistema del Acuifero Guarani del 2 de agosto de 2010 en el marco de la incipiente regulación general de las aguas subterráneas, en Derecho de Aguas, Tomo V (Bogotá, Universidad Externado de Colombia, 2013), pp. 179-210.

EMBID, Antonio, Organizaciones de usuarios y participación en la gestión del agua en el Derecho español: reflexiones generales y consideración de la reciente legislación peruana de aguas sobre estas cuestiones, en URTEAGA, Patricia - Verona, Aarón (editores), Cinco años de la Ley de Recursos Hidricos en el Perú. Segundas Jornadas de Derecho de Aguas (Lima, Centro de Investigación, Capacitación y Asesoría Jurídica Departamento Académico de Derecho, Pontificia Universidad Católica del Perú, 2015), pp. 229-249.

ENDO, Takahiro, Groundwater management: a search for better policy combination, en Water Policy 17 (2015), pp. 332-348.

GetChes, David, Controlling groundwater use and quality: a fragmented system, en Natural Resources Lawyer 17 (1985) 4, pp. 623-645.

Giordano, Mark y SHAH, Tushaar, From IWRM back to integrated resources management, en International Journal of Water Resources Development 30 (2014) 3, pp. 364-376.

Godden, Lee y KunG, Anthony, Water Law and planning frameworks under climate change variability: systemic and adaptive management of flood risk, en Water Resources Management 25 (2011), pp. 4051-4068.

Gorelick, Steven y ZHENG, Chunmiao, Global change at the groundwater management challenge, en Water Resources Research 51 (2015) 5, pp. 3031-3051.

GRIGG, Neil, Integrated water resources management: balancing views and improving practice, en Water International 33 (2008) 3, pp. 279-292.

HedGes, John, Currents in California Water Law: the push to integrate groundwater and surface water management through the Courts, en Water Law Review 14 (20102011) 2, pp. 375-401.

Holley, Cameron y SinClair, Darren, Collaborative governance and adaptive mana- 
gement: (mis)applications to groundwater, salinity and run-off, en The Australasian Journal of Natural Resources Law and Policy 14 (2011) 1, pp. 37-69.

-Deliberative participation, environmental law and collaborative governance: insights from surface and groundwater studies, en Environmental and Planning Law Journal 30 (2013) 32, pp. 32-55.

Kiparsky, Michael, Owen, Dave, Green Nylen, Nell, Christian-Smith, Juliet, Cosens, Barbara, Doremus, Holly, Fisher, Andrew y Milman, Anita, Designing effective groundwater sustainability agencies: criteria for evaluation of local governance options (Berkeley, Wheeler Water Institute-Center for Law, Energy \& the Environment, UC Berkeley School of Law, 2016), 63 pp.

LANGRIDGE, Ruth, Drought and groundwater: legal hurdles to establishing groundwater drought reserves in California, en University of California, en Davis Law Review 36 (2012) 1, pp. 91-113.

-Confronting drought: water supply planning and the establishement of a strategic groundwater reserve, en Water Law Review 12 (2009) 2, pp. 295-331.

Legislative AnAlyst's OfFice (LAO), Improving management of the State's groundwater resources (Sacramento, LAO Ediciones, 2010), $24 \mathrm{pp}$.

LÓPEZ-GunN, Elena y RicA, Marta, La participación activa de los usuarios: la co-gestión como forma de gobernanza del agua subterránea, en LAS MISMAS (coordinadoras), Gestión colectiva del agua subterránea en España (Madrid, Fundación Botín, 2013), pp. 15-35.

LOPEZ-GunN, Elena y JARVIS, Todd, Groundwater governance and the Law of the Hidden Sea, en Water Policy 11 (2009), pp. 742-762.

Llamas, M.R. y MartíneZ-SANTOS, P., Intensive groundwater use: silent revolution and potencial source of social conflicts, en Journal of Water Resources Planning and Management (2005), pp. 337-342.

Llamas, M. Ramón, Custodio, Emilio, De la Hera, A. y Fornés, J.M., Groundwater in Spain: increasing role, evolution, present and future, en Environmental Earth Sciences 73 (2015), pp. 2567-2578.

MaCNAUghton, Ann y FOLK-WILliams, John, Engaging stakeholders for sustainable water resource solutions, en Natural Resources \& Environment 18 (2003) 2, pp. 36-40.

MeCHLEM, Kerstin, Groundwater governance: a global framework for country action. Legal and institutional frameworks (Rome, Groundwater Governance, 2012), 46 pp.

Ministerio de Obras Públicas y Dirección General de Aguas, Estrategia Nacional de Recursos Hidricos (Santiago, MOP, 2013), 40 pp.

-Atlas del Agua. Chile 2016 (Santiago, MOP, 2016), 137 pp.

Muñoz, Jaime, Gestión de acuiferos. Disponibilidad técnica y jurídica de aguas subterráneas, en Revista de Derecho Administrativo Económico I (1999) 2, pp. 315-323.

MuÑoz, Gonzalo, El registro de las organizaciones de usuarios de aguas por la Dirección General de Aguas, en Revista de Derecho Administrativo Económico 2 (2003), pp. 303-309.

Neumann, Christian, Aspectos generales, derechos y obligaciones en las organizaciones de usuarios de aguas, en Revista de Derecho Administrativo Económico III (2001) 2, pp. 577-616.

NANNI, Marcella, Legislation as a tool in support of adaptive water management in response to climate change, en Water International 37 (2012) 6, pp. 628-639.

Neuman, Janet, Drought proofing Water Law, en Water Law Review 7 (2003-2004), pp. 105-110. 
Organisation for eConomic COOperation and DeVelopment (OECD), Principles on water governance (s/l, OECD, 2015), $23 \mathrm{pp}$.

Ostrom, Elinor, El gobierno de los bienes comunes. La evolución de las instituciones de acción colectiva ( $2^{\text {a }}$ edición en español, traducción castellana de L. Merino, Ciudad de México, Instituto de Investigaciones Sociales Universidad Nacional Autónoma de México y Fondo de Cultura Económica, 2011), 403 pp.

- Comprender la diversidad institucional (traducción castellana de M. Moro, Oviedo, KRK, 2013), 757 pp.

-Collective action and the evolution of social normas, en Journal of Natural Resources Policy Research 6 (2014) 4, pp. 235-252.

Peralta, Fernando, Aguas subterráneas, un recurso inexplorado y desconocido, en Derecho en la Región I (1993) 1, pp. 37-46.

ROJAs, Christian, La distribución de aguas por las juntas de vigilancia, en Revista de Derecho Administrativo Económico 2 (2003), pp. 317-326.

-Autogestión y autorregulación regulada de las aguas. Organizaciones de usuarios de aguas (OUA) y juntas de vigilancia de ríos, en Ius et Praxis 20 (2014) 1, pp. 123-162.

-La categoría jurídica de los "servicios privados de interés publico": el caso de las juntas de vigilancia de los ríos, en Revista Chilena de Derecho 41 (2014) 1, pp. 171-204.

SANDINO, David, California's groundwater management since the Governos's Commission Review: the consolidation of local control, en McGeorge Law Review 36 (2005), pp. 471-494.

SARKER, Ashutosh, BALDWIN, Claudia y Ross, Helen, Managing groundwater as a common-pool resource: an australian case study, en Water Policy 11 (2009), pp. 598-614.

SCHLAGER, E. y LóPEZ-GunN, E., Collective systems for water management: is the tragedy of the commons a myth? en Rogers, Peter - Llamas, M. Ramón - MarTínez-Cortina, Luis (editores), Water crisis: myth or reality? (Londres, Taylor \& Francis/Balkema, 2006), pp. 43-58.

STEVENS, Jan, California's groundwater: a legally neglected resource, en Hastings WestNorthwest Journal of Environmental Law and Policy 19 (2013) 1, pp. 4-40.

THOMPSON, Barton, Beyond connections: pursuing multidimensional conjunctive management, en Idaho Law Review 47 (2011), pp. 273-323.

Vergara, Alejandro, Autogobierno en la gestión de las aguas, en Actas de Derecho de Aguas 3 (2013), pp. 165-174.

Vergara, Alejandro, Crisis institucional del agua. Descripción del modelo, critica a la burocracia y necesidad de tribunales especiales (Santiago, LegalPublishing Chile, 2014), 508 pp.

\section{JURISPRUDENCIA}

Corte de Apelaciones de San Miguel, Reyes Zapata, Jorge, Rol No 2052-2016, 14 de abril de 2016. Identificador LegalPublishing: CL/JUR/2494/2016.

Corte Suprema, Junta de Vigilancia de la Tercera Sección del Río Aconcagua con Junta de Vigilancia de la Primera Sección del Río Aconcagua, Rol No 2014-2014, 25 de marzo de 2014. Identificador LegalPublishing: CL/JUR/513/2014. 